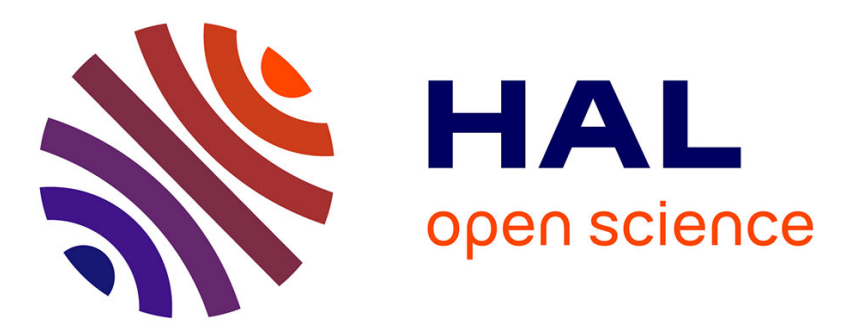

\title{
Model reduction and model predictive control of energy-efficient buildings for electrical heating load shifting
}

\author{
M. Robillart, P. Schalbart, B. Peuportier, François Chaplais
}

\section{- To cite this version:}

M. Robillart, P. Schalbart, B. Peuportier, François Chaplais. Model reduction and model predictive control of energy-efficient buildings for electrical heating load shifting. Journal of Process Control, 2018, 10.1016/j.jprocont.2018.03.007 . hal-01965265

\section{HAL Id: hal-01965265}

https: / hal-mines-paristech.archives-ouvertes.fr/hal-01965265

Submitted on 22 Oct 2021

HAL is a multi-disciplinary open access archive for the deposit and dissemination of scientific research documents, whether they are published or not. The documents may come from teaching and research institutions in France or abroad, or from public or private research centers.
L'archive ouverte pluridisciplinaire HAL, est destinée au dépôt et à la diffusion de documents scientifiques de niveau recherche, publiés ou non, émanant des établissements d'enseignement et de recherche français ou étrangers, des laboratoires publics ou privés.

\section{()ㅜ(1)}

Distributed under a Creative Commons Attribution - NonCommerciall 4.0 International 


\title{
Model reduction and model predictive control of energy- efficient buildings for electrical heating load shifting
}

\author{
M. Robillart ${ }^{1}$, P. Schalbart ${ }^{1}$, F. Chaplais ${ }^{2}$, B. Peuportier ${ }^{1}$ \\ ${ }^{(1)}$ MINES ParisTech, PSL Research University, CES - Centre for energy efficiency of systems, 60 \\ Bd St Michel 75006 Paris, France
}

${ }^{(2)}$ MINES ParisTech, PSL Research University, CAS - Centre for automatic control and systems theory, 60 Bd St Michel 75006 Paris, France

\begin{abstract}
In France, buildings account for a significant portion of the electricity consumption (around $68 \%$ ), due to an important use of electrical heating systems. This results in high peak load in winter and causes tensions on the production-consumption balance. In view of reducing such fluctuations, advanced control systems (including the Model Predictive Control framework) have been developed to shift heating load while maintaining indoor comfort and taking advantage of the building thermal mass. In this paper, a framework for developing optimisationbased control strategies to shift the heating load in buildings is introduced. The balanced truncation method and a time-continuous optimisation method were used to develop a real-time control of the heating power. These two methods are well suited for control problems and yield precise results. The novelty of the approach is to use reduced models derived from advanced building simulation software. A simulation case study demonstrates the controller performance in the synthesis of a predictive model-based optimal energy management strategy for a single-zone test building of the "INCAS" platform built in Le Bourget-du-Lac, France, by the National Solar Energy Institute (INES). The controller exhibits excellent performance, reaching between 6 and $13 \%$ cost reduction, and can easily be applied in real-time.
\end{abstract}

Keywords: Model Predictive Control, model reduction, load shifting, buildings

\section{INTRODUCTION}

Over $68 \%$ of the final electricity consumption in France can be attributed to the building sector [1]. In addition to being a large producer of greenhouse gases emissions, buildings represent a key component of peak electricity demand during winter periods, mainly due to heating systems. Consumption peak periods are difficult to handle and may disrupt the electricity productionconsumption balance. Electricity producers and grid operators generally invest in peak production facilities and distribution capacities incurring additional economic and environmental costs. 
An alternative to this solution consists in developing smart electric grid and implementing smart programs of energy management. Demand response (DR) strategies have an appealing potential to reduce electricity peak demand. These techniques aim at modifying consumers' demand for energy through various methods such as financial incentives or information. A key factor in the growth of DR strategies (as peak shifting and load levelling strategies) is the availability of energy storage capacities to shift electricity consumption from peak to off-peak periods. Active and passive thermal energy storage can be used to meet such objectives. On the one hand, heating, ventilation and air conditioning (HVAC) systems can be designed with tanks that store energy (e.g. chilled or hot water). For instance, [2] proposed a strategy for the optimal control of building HVAC systems with chilled water thermal energy storage. They proposed a hierarchical Economic Model Predictive Control (E-MPC) framework based on different time scales (scheduling and control perspectives) and decision variables. In the same way, [3] developed an optimisation algorithm for load-shifting of large sets of electric hot water tanks. On the other hand, the thermal mass of the building can be used to retain and release energy [4]. For instance, [5] showed that it is possible to shift the load of heating to off-peak hours in the case of highly insulated buildings with high thermal mass. Finally, passive building thermal capacitance and active thermal energy storage systems can be both combined requiring a coordination of the charge and discharge events $[6,7]$.

The peak electricity demand can be decreased by developing new advanced control techniques accessible to building designers and operators. The optimisation-based control strategies have consequently to be able to coordinate (taking into account the uncertainty) the charge and discharge events with external factors such as energy prices, occupancy and weather. The use of Model Predictive Control (MPC) paradigm is useful owing to its ability to address an energy management optimisation problem while satisfying constraints (e.g. thermal comfort) and accounting for forecast of disturbances (e.g. weather forecast). This approach poses a number of significant challenges. In addition to imposing a more complex IT infrastructure (hardware and software), MPC implementation requires an accurate building model that can be run rapidly and repeatedly in real-time. However, advanced building simulation software (e.g. EnergyPlus or TRNSYS) require too much computation time for online calculations. To overcome this problem, several approaches have been employed to identify simplified building models which can be used in the MPC framework. A number of articles discuss the use of resistance-capacitance (RC) network models [8], data-driven methods such as neural network models [9], or the identification of linear state-space models based on data obtained from detailed simulation software [10]. Although these models are convenient for MPC implementation, they may be inaccurate when the operating conditions deviate from those used during the identification process. An alternative is to use reduced models derived from advanced building simulation software which is the main contribution of this study.

In this paper, we introduce a framework for developing optimisation-based control strategies to shift the heating load in buildings. Section 2 introduces the dynamic building energy model and the applied model reduction technique. The optimisation algorithm used to solve the optimal control 
problem is described in section 3. Section 4 explains in detail the MPC design and implementation. Finally, in section 5, simulation results are presented and discussed.

\section{REDUCED MODEL FOR MPC}

\subsection{Building description}

The case study is a two-storey experimental passive house of the "INCAS" platform built in Le Bourget-du-Lac, France, by the National Solar Energy Institute (INES). The house is made of shuttered concrete ( $15 \mathrm{~cm}$ thick) with external insulation ( $20 \mathrm{~cm}$ of extruded polystyrene), and has a heavy ground floor (24 cm concrete slab and $20 \mathrm{~cm}$ external insulation), a heavy intermediate floor $(16 \mathrm{~cm}$ concrete screeds and girders and $12 \mathrm{~cm}$ overlaying concrete slab floor) and a lightweight ceiling ( $1 \mathrm{~cm}$ gypsum board and $40 \mathrm{~cm}$ of glass wool). The building's facades include double glazing (mainly on the south facade) and triple glazing on the north facade. The total living surface area is $89 \mathrm{~m}^{2}$. Thanks to careful design and construction phases, thermal bridges and air infiltration are low. The building has an electrical heating system. The mechanical ventilation corresponds to 0.6 air change per hour $(\mathrm{ACH})$ to guarantee sufficient air renewal. A heat exchanger allows heat recovery from exhaust air with an efficiency of $90 \%$. In order to reduce calculation time of the optimisation algorithm, the house was modelled as a single zone.

The stochastic model developed by [11] was used to generate an occupancy scenario. Realistic inhabitants' characteristics and behaviours are represented through a probabilistic approach based on multiple statistical data (e.g. French socio-demographic and time-use survey but also measurement campaigns). For each simulation, a stochastic process sets users' characteristics and presence scenarios depending on the household socio-demographic attributes. From several hundred simulations of this model, an average occupancy scenario was created. We considered a three people household with high performance appliances and lighting. Figure 1 presents the internal gains average scenario in the building during a winter week derived from a sample of 300 generated scenarios. 


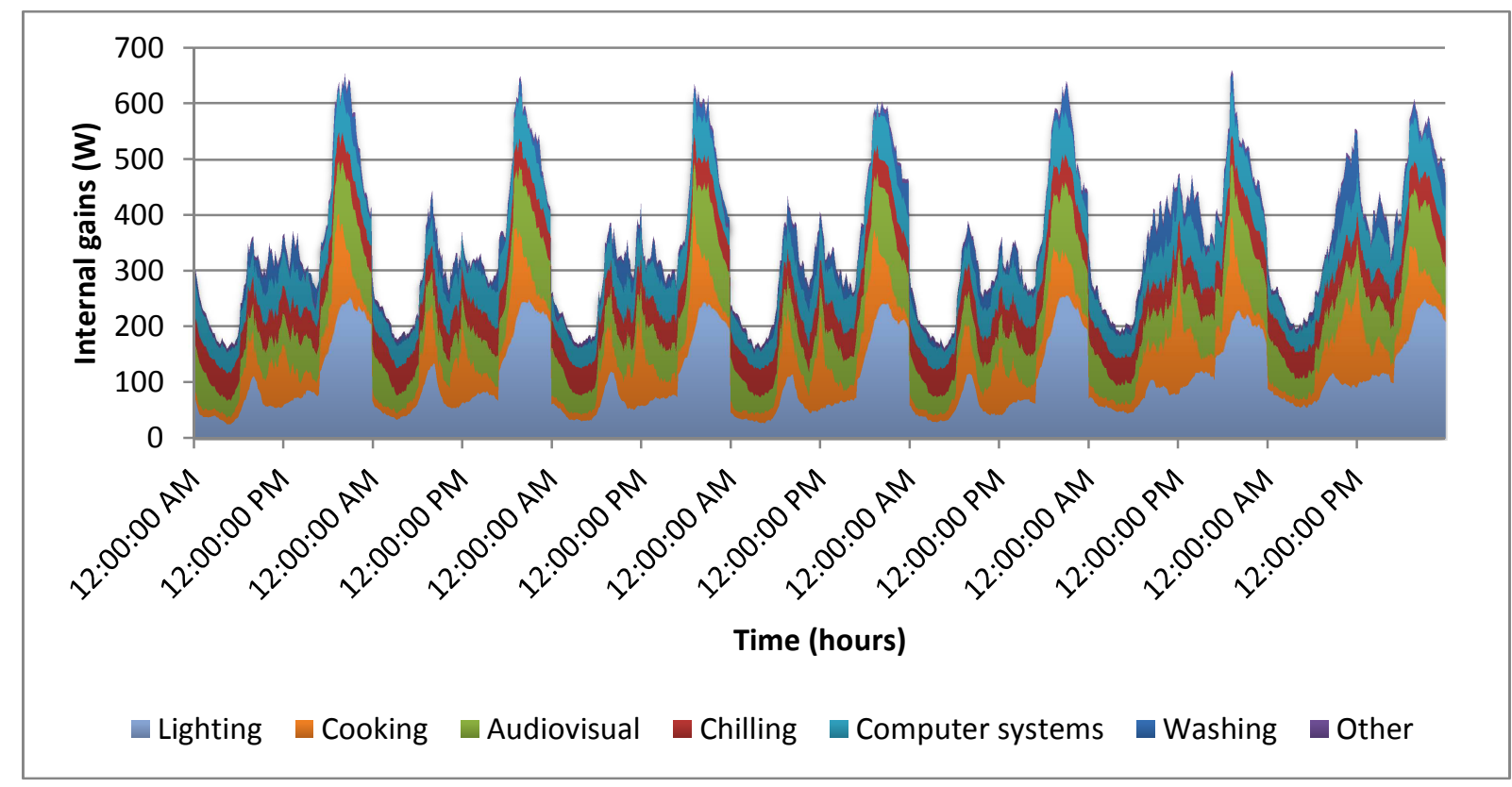

Figure 1: Generated average internal gains scenario in a dwelling occupied by three inhabitants during a winter week

\subsection{Thermal model of the building}

In this study, the dynamic building energy software COMFIE, developed by [12], was used to obtain the thermal model of the building. This model relies on the concept of thermal zone which is a part of the building (generally comprising one or more rooms) with a homogeneous temperature. For each zone, each wall is divided in meshes according to the finite volume technique, each mesh being associated with a uniform temperature and a thermal capacity. To ensure this hypothesis, the mesh size is finer as the mesh is close to the inner surface. Another mesh is added for the zone's air and furniture. Energy conservation equations are applied on each mesh within the building [13]:

$$
C_{m} d T_{m} / d t=\dot{Q}_{G}-\dot{Q}_{L}
$$

with

- $C_{m}$ the thermal capacity of the mesh,

- $T_{m}$ the temperature of the mesh,

- $\dot{Q}_{G}$ the solar and internal gains (due to heating, occupancy and other appliances),

- $\dot{Q}_{L}$ the linearised heat losses by conduction, convection and radiation.

Repeating energy balance on each mesh leads to a linear time-invariant system [14,15], nonlinear phenomena and variable parameters (ventilation, thermal resistance added due to intermittent use of shutters, etc.) being integrated in the driving forces (the state-space representation is considered in this study): 


$$
\begin{aligned}
& \dot{x}(t)=A x(t)+B u(t) \\
& y(t)=C x(t)+D u(t)
\end{aligned}
$$

with

- $x \in \mathbb{R}^{q}$ ( $q=28$ in this study) the state of the building (the energy stored in each mesh),

- $u \in \mathbb{R}^{m}$ ( $m=10$ in this study) the driving forces (climate parameters, heating, etc.),

- $y \in \mathbb{R}$ the zone temperature (accounting for air and wall surfaces),

- $A, B, C, D$ the state, input, output and feedforward matrices, respectively.

The occupancy schedule of the building which defines the emission of heat by the inhabitants and appliances, and the thermostat setpoint influencing the heating equipment, as well as the climatic data influencing heat losses and solar gains must be specified. The data regarding house occupancy and weather are included in the driving forces vector $u$. On top of several validation studies [16], the model's reliability was studied in the particular context of a high performance houses and is comparable to international reference models [17-19].

\subsection{Model reduction}

In view of application of optimisation methods, the high order linear model (2) (obtained by the dynamic building energy software COMFIE) was reduced. Its original state dimension (order 28) was too large to allow a fast convergence of the optimisation algorithm. Fast convergence of the optimisation algorithm was achieved by reducing the high order of the system (2). To do so, several methods exist such as the modal reduction [20], the proper orthogonal decomposition [21], or the singular value decomposition [22]. In our case, the balanced truncation method [23] was selected because it is an efficient method that presents a good reliability and it is commonly used for control applications [24].

Identification of the order of the reduced model requires the determination of the balanced reduced states which are completely controllable and completely observable. In this study, the order reduction had to be smaller than or equal to four to obtain a completely controllable and observable model. In Table 1, the various time constants of the reduced order are reported. One can notice that these thermal building models clearly have well separated time constants. 
Table 1: Value of the time constants of the four reduced models

\begin{tabular}{|c|c|c|c|c|}
\hline Reduction order & 1 & 2 & 3 & 4 \\
\hline & & & 17 days & 20 hours \\
Time constants & \multirow{3}{*}{16 days } & 17 days & 1 hour & 44 minutes \\
& & 13 minutes & 8 minutes & 6 minutes \\
\hline
\end{tabular}

In order to calculate the optimal control of the heating power, it is essential to consider a reduced order model which warrants a numerical equivalence with the reference model. To determine the suitable reduced order model (which is a compromise between accuracy and calculation time), frequency and time-domain analyses were carried out. For the frequency analysis, three driving forces were considered: the heating power (which is the control variable), the outdoor temperature and the solar radiation through windows.

Figure 2 shows the Bode diagram for the transfer functions (heating power $\rightarrow$ indoor temperature) calculated with the reference model (blue line) and with the $1^{\text {st }}$ and $2^{\text {nd }}$ order models (red and green lines respectively). Substantial differences (both in magnitude and phase) can be observed between the $1^{\text {st }}$ order model and the reference model. For example, a delay can be observed for frequencies between $10^{-6} \mathrm{~Hz}$ and $10^{-2} \mathrm{~Hz}$ (corresponding to time periods between one minute and several days). This reduced model was consequently not able to correctly represent the evolution of the indoor temperature. The $2^{\text {nd }}$ order model presented a different behaviour. For example, it had a phase delay for time periods between one and several minutes and a phase advance for time periods corresponding to several hours. Thus, this reduced model tended to underestimate the indoor temperature variation for heating power variations over a few minutes and to overestimate the indoor temperature variation over several hours. Consequently, the $1^{\text {st }}$ and $2^{\text {nd }}$ order models did not qualify as relevant reduced order models. 


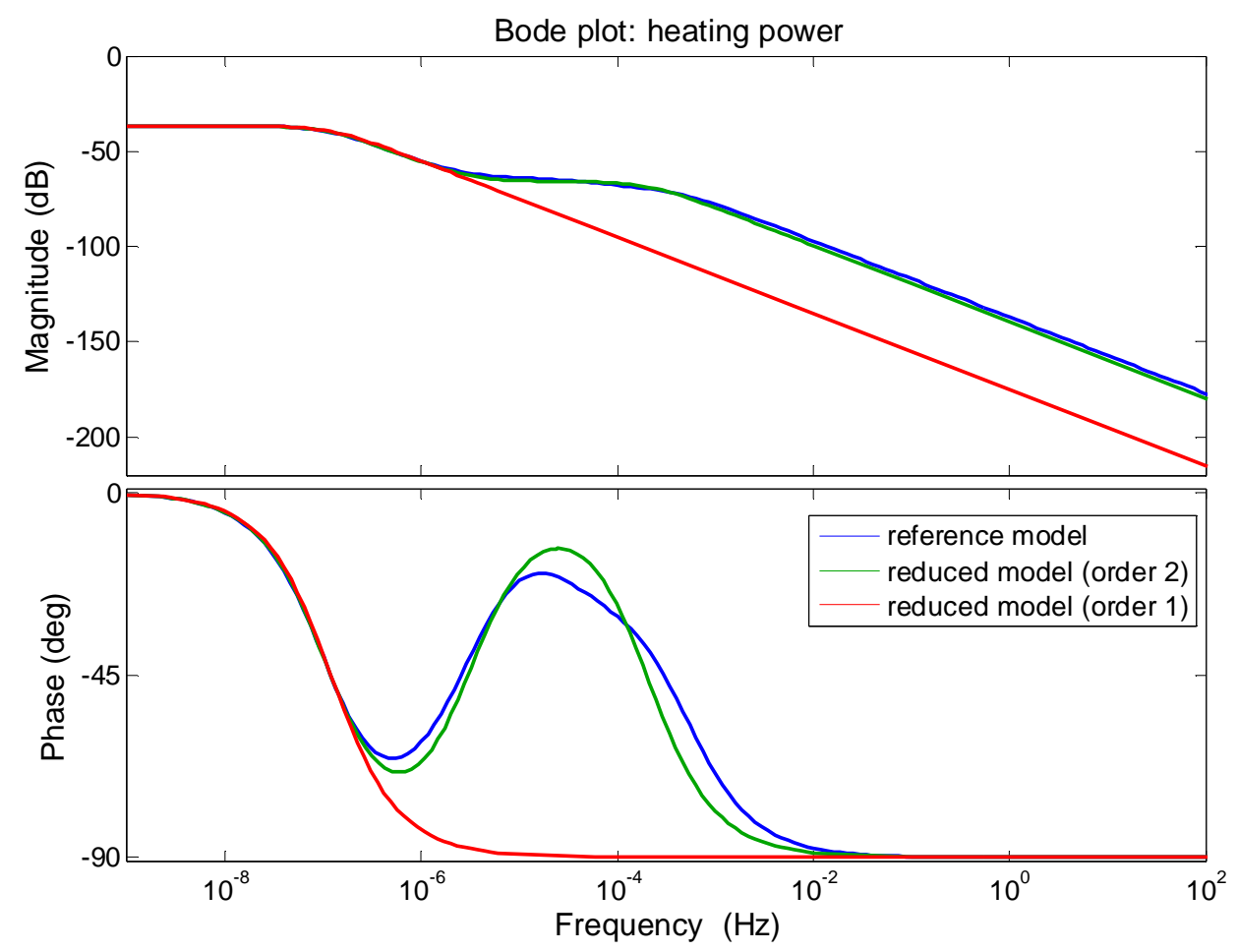

Figure 2: Frequency response of the reference and $1^{\text {st }}$ and $2^{\text {nd }}$ order models to the heating power

Figure 3 illustrates the Bode diagram for the transfer functions (heating power $\rightarrow$ indoor temperature) calculated with the reference model (blue line) and with the $3^{\text {rd }}$ and $4^{\text {th }}$ order models (red and green lines respectively). An excellent agreement can be observed. Similar results (Figure 4) were obtained for the other transfer function (outdoor temperature $\rightarrow$ indoor temperature). 


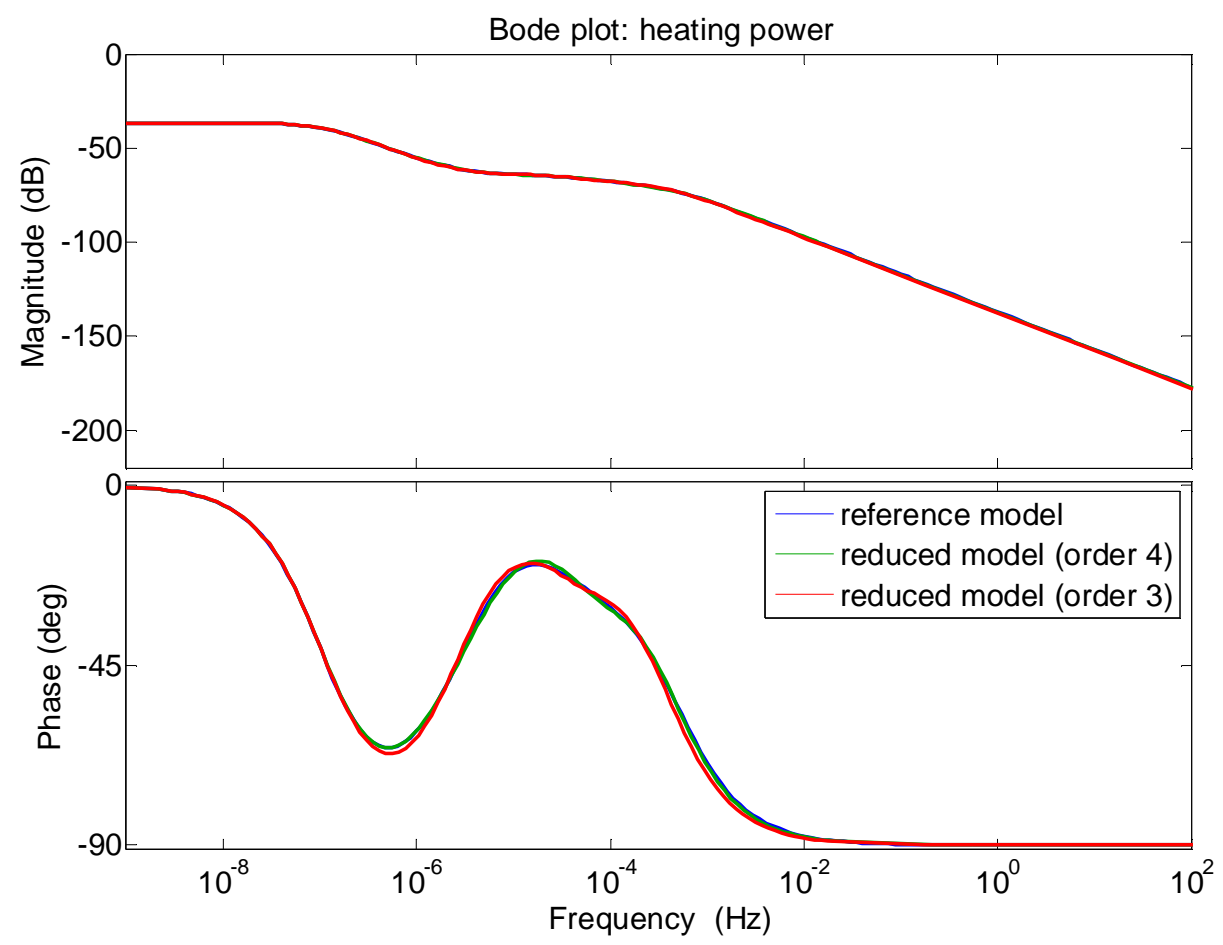

Figure 3: Frequency response of the reference and $3^{\text {rd }}$ and $4^{\text {th }}$ order models to the heating power

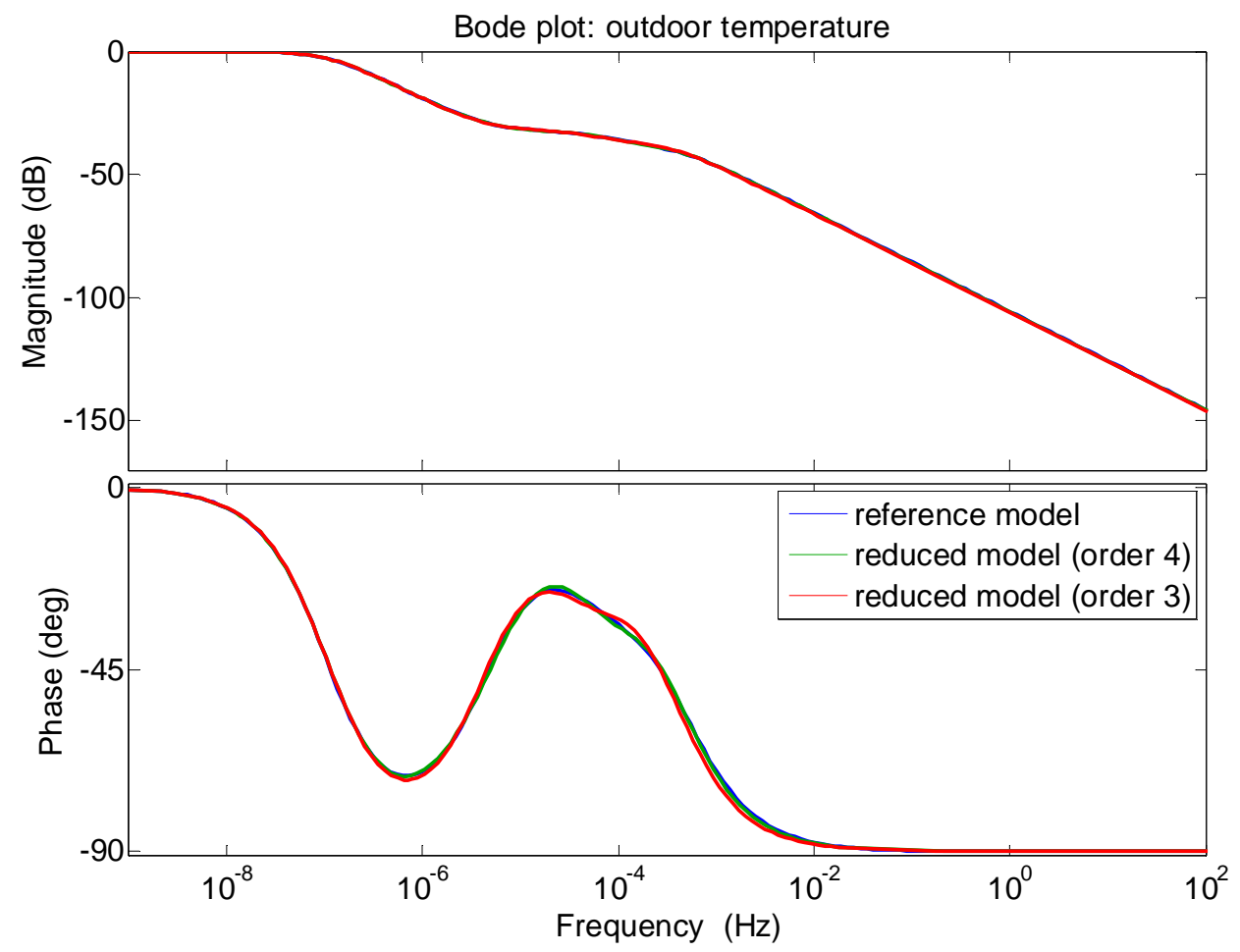

Figure 4: Frequency response of the reference and $3^{\text {rd }}$ and $4^{\text {th }}$ order models to the outdoor temperature

Some differences (Figure 5) can be observed for the transfer function (solar radiation through windows $\rightarrow$ indoor temperature). The reduced models had a phase advance for time periods 
between one second and several hours. From a physical point of view, this mistake can be explained by the inability of the reduced models to faithfully represent the impact of solar radiation through windows.

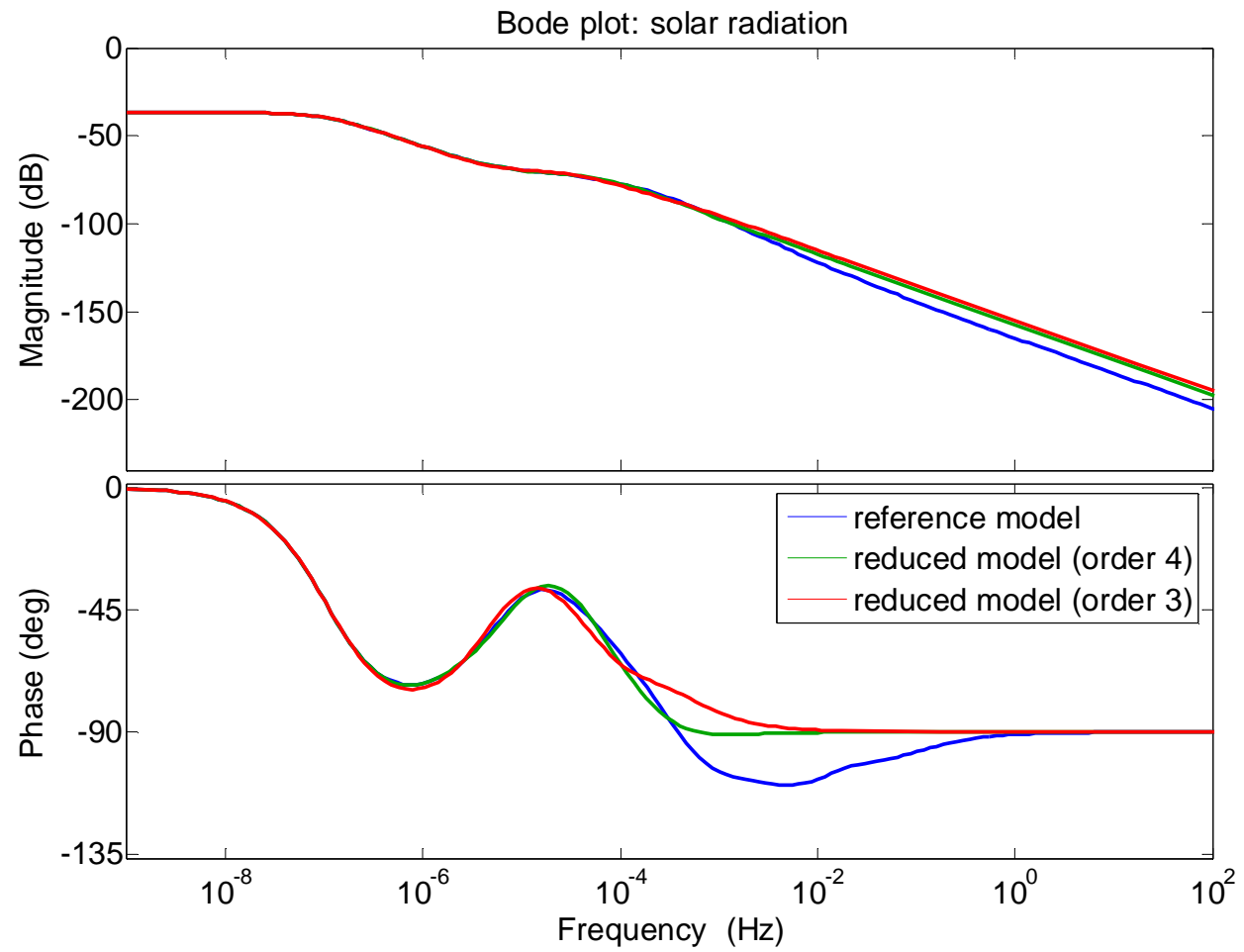

Figure 5: Frequency response of the reference and $3^{\text {rd }}$ and $4^{\text {th }}$ order models to the solar radiation

The frequency analysis of the reference model and the reduced models of order 3 and 4 presented a good concordance. To choose between the reduced models ( $3^{\text {rd }}$ and $4^{\text {th }}$ order models), a time domain analysis was carried out. We compared the zone temperature predicted by the reference model and by the reduced models while the building was in free-running mode (i.e. not heated). Three-months (from January to March) Typical Meteorological Year-type (TMY) data from Chambéry (France), a city near Le Bourget-du-Lac, were considered. Figure 6 illustrates the indoor temperature, on the day when the root-mean-square error (RSME) was the highest for the $3^{\text {rd }}$ order model, predicted by the reference model and by the reduced models. A good agreement can be observed, especially for the $4^{\text {th }}$ order model. Furthermore, the RMSE of the $3^{\text {rd }}$ and $4^{\text {th }}$ order models on the three months were small: respectively $0.0368^{\circ} \mathrm{C}$ and $0.0082^{\circ} \mathrm{C}$. Consequently, as the results of these reduced models were close, the $3^{\text {rd }}$ order model was chosen because it represented a reasonable compromise between the accuracy of the results and calculation time. 


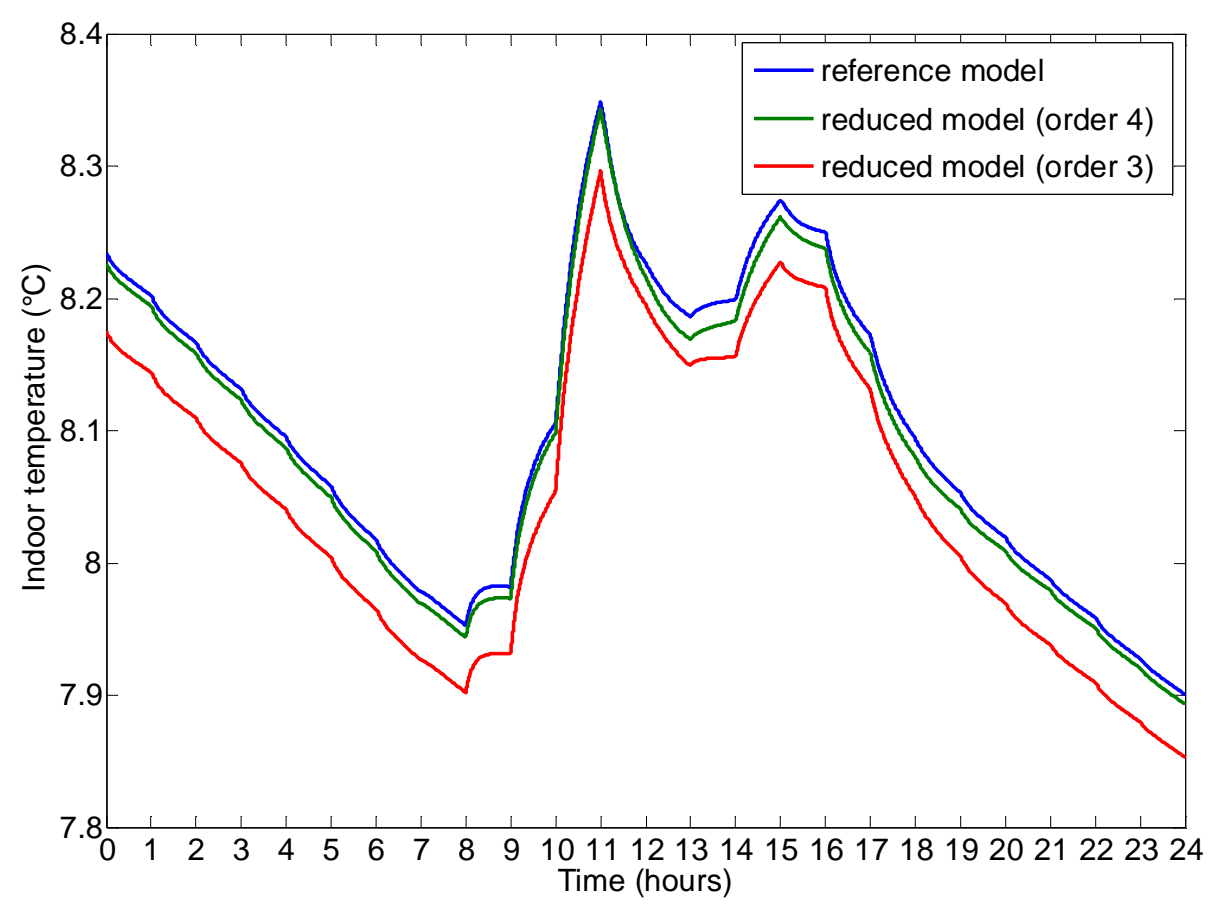

Figure 6: Indoor temperature predicted by the reference and reduced models on the day when the RMSE was the highest

\section{OPTIMAL CONTROL PROBLEM}

In the Demand Response context, the energy management optimisation in individual houses consists in solving a state and input constrained optimal control problem. This section exposes a methodology to solve it.

We consider the following constrained optimal control problem:

$$
\min _{u \in U \cap X}\left[J(u)=\int_{0}^{t_{f}} \mathcal{L}(x(t), u(t)) d t\right]
$$

where $\mathcal{L}$ is a smooth real-valued function of its arguments, under the following dynamical constraints:

$$
\dot{x}^{u}=f\left(x^{u}(t), u(t)\right) ; \quad x(0)=x_{0}
$$

corresponding to the balanced reduced state-space representation of the time-invariant linear system (2), where $x(t) \in \mathbb{R}^{n}$ and $u(t) \in \mathbb{R}^{m}$ are respectively the state and the control (in this study $n=3$ and $m=10$ ), and $x_{0}$ is the initial state of the building (which can be estimated by a state observer). A solution of (2) with input $u$ is noted $x^{u}$. The set $U \cap X$ is defined by control and state constraints considering inequality state constraints and control constraints under the form $u(t) \in \mathrm{C}$ (where $C$ is a bounded closed convex set). The optimal control problem consists in finding the control $\mathrm{u}$ and its associated states $x^{u}$ solution of (4) and minimising the integral cost (3) while respecting 
state and control constraints. An interior penalty method was used to solve this constrained optimal control problem.

\subsection{Interior penalty algorithm}

The main idea driving penalty methods is to consider an augmented cost constructed by adding a term, called penalty function, to the original cost function. This penalty function has a diverging behaviour when the constraints are approached by a solution. Thus, penalty methods attempt to approximate a constrained optimal control problem with a series of unconstrained optimal control problems and then apply standard techniques to obtain solutions. Satisfaction of the constraints is favoured by the augmented cost and depends on the weight of the penalty function.

The algorithm used in this study is based on an interior penalty method, with penalty functions $\gamma_{g}$ and $\gamma_{u}$ and a generalised saturation function $\phi(v)=u$ (allowing to remove the constraint) to formulate the following problem:

$$
\min _{v \in L^{\infty}\left(\left[0, t_{f}\right], \mathbb{R}^{m}\right)} \int_{0}^{t_{f}} \mathcal{L}\left(x^{\phi(v)}, \phi(v)\right) d t+\varepsilon \int_{0}^{t_{f}}\left(\gamma_{g}\left(x^{\phi(v)}\right)+\gamma_{u}(v)\right) d t
$$

where $\gamma_{g}$ and $\gamma_{u}$ are the state penalty function and the control penalty function respectively. [25] showed that this problem generated, as $\varepsilon \rightarrow 0$, a sequence of solutions converging to a solution of the constrained optimal control problem (3). Each solution of the sequence is readily characterised by the calculus of variations as the problem (5) is unconstrained. More precisely, the conditions of the Pontryagin Minimum Principle [26] are exploited. Algorithm description, convergence results and definition of penalty functions can be found in [25]. To solve the penalised problem (5), the Hamiltonian of the problem is defined (where $p \in \mathbb{R}^{n}$ is the adjoint vector):

$$
H_{\varepsilon}\left(x^{\phi(v)}, v, p\right)=\mathcal{L}\left(x^{\phi(v)}, \phi(v)\right)+\varepsilon\left[\gamma_{g}\left(x^{\phi(v)}\right)+\gamma_{u}(v)\right]+p^{t} f\left(x^{\phi(v)}, \phi(v)\right)
$$

\subsection{Application}

\subsubsection{Constrained optimal control problem}

In this study, a state and input constrained optimal control problem was to be solved. The goal of the optimisation was to minimise the heating cost of a building by determining the optimal trajectory with constraints on thermal comfort (state constraints) and heating power (control constraints).

The classical linear state space representation was used for the $3^{\text {rd }}$ order model where the driving forces vector $u$ was divided into the heating power $P$ (the control variable) and the vector $d$ representing the influence of the outside temperature, the solar fluxes, the occupancy and other appliances: 


$$
\begin{gathered}
\dot{x}(t)=A x(t)+B_{P} P(t)+B_{d} d(t) \\
T(t)=C x(t)
\end{gathered}
$$

with

- $x$ the state of the building,

- $T$ the indoor temperature,

- $B_{P}$ and $B_{d}$ the input matrices related to $P(t)$ and $d(t)$.

An acceptable level of comfort was ensured by maintaining indoor temperature between $19^{\circ} \mathrm{C}\left(T_{\min }\right)$ and $24^{\circ} \mathrm{C}\left(T_{\max }\right)$. The heating power could vary between $0 \mathrm{~W}\left(P_{\min }\right)$ and $5000 \mathrm{~W}\left(P_{\max }\right)$. Thus, the finite-horizon decision problem took the following form:

$$
\min _{P} \int_{0}^{t_{f}} C_{\text {elec }}(t) P(t) d t
$$

with

- $C_{\text {elec }}$ the dynamic electricity cost,

- $t_{f}$ the duration of the optimisation period.

State and control constraints were defined as follows:

$$
\begin{aligned}
& T_{\min } \leq T(t) \leq T_{\text {max }} \\
& P_{\text {min }} \leq P(t) \leq P_{\text {max }}
\end{aligned}
$$

In the Demand Response context, a time-of-use pricing was considered to shift the electricity demand. Adapted from the current prices in France by adding peak hour rates allowing load shifting, the electricity prices considered in this study are shown in Table 2.

Table 2: Electricity prices

\begin{tabular}{|c|c|c|c|}
\hline & Off-peak hours & Peak hours & High peak hours \\
\hline Hours & 12 a.m. to 9 a.m. & $\begin{array}{r}9 \text { a.m. to } 5 \text { p.m. } \\
10 \text { p.m. to } 12 \text { a.m. }\end{array}$ & 5 p.m. to 10 p.m. \\
\hline Cost per kWh $(€)$ & 0.0864 & 0.1275 & 0.255 \\
\hline
\end{tabular}

\subsubsection{Numerical resolution of the constrained optimal control problem}

To solve the constrained optimal control problem, the interior-point algorithm described in [25] was used. In this study, to remove the input constraint, the following change of variables was considered [27]:

$$
P=\phi(v)=P_{\max }\left(\frac{e^{k v}}{1+e^{k v}}\right), k>0
$$

Thus, the Hamiltonian of the penalised optimal control problem was:

$$
\begin{aligned}
& H_{\varepsilon}(x, v, p)=C_{e l e c} \phi(v)+p^{t}\left(A x+B_{P} \phi(v)+B_{d} d\right) \\
& +\varepsilon\left[\gamma_{g}\left(C x-T_{\min }\right)+\gamma_{g}\left(T_{\max }-C x\right)+\gamma_{u} \circ \phi(v)\right]
\end{aligned}
$$


The adjoint vector $p$ must satisfy the following differential equation:

$$
\frac{d p}{d t}(t)=-\frac{\partial H_{\varepsilon}}{\partial x}(x, v, p)=-A^{t} p(t)-\varepsilon C^{t}\left[\gamma_{g}^{\prime}\left(C x(t)-T_{\min }\right)-\gamma_{g}^{\prime}\left(T_{\max }-C x(t)\right)\right]
$$

where $\gamma_{g}^{\prime}$ is the derivative of the function $\gamma_{g}$ defined as:

$$
\gamma_{g}(s)=\left\{\begin{array}{l}
s^{-1.1} \forall s>0 \\
0 \quad \text { otherwise }
\end{array}\right.
$$

The algorithm used to solve the constrained optimal control problem was the following:

- Step 1: Initialise the continuous functions $x(t)$ and $p(t)$ such that the initial value $C x(t) \in\left[T_{\min }, T_{\text {max }}\right]$ for all $t \in\left[0, t_{f}\right]$. At first, $p(t)$ can be chosen identically equal to zero. Set $\varepsilon=\varepsilon_{0}$.

- Step 2: Compute $v_{\varepsilon}^{*}=\sinh ^{-1}\left(-\frac{C_{\text {elec }}(t)+p^{t}(t) B_{P}}{\varepsilon}\right)$ the analytical solution of $\frac{\partial H_{\varepsilon}}{\partial v}=0^{1}$ where we set $\gamma_{u}^{\prime} \circ \phi(v)=\sinh (v)$.

The optimal solution $P_{\varepsilon}^{*}(t)=\phi\left(v_{\varepsilon}^{*}(t)\right)$ is given using equation (11).

- Step 3: Solve the $2 n$ differential equations

$$
\left\{\begin{array}{c}
\frac{d x(t)}{d t}=A x(t)+B_{P} P_{\varepsilon}^{*}(t)+B_{d} d(t) \\
P_{\varepsilon}^{*}(t)=\phi\left(\sinh ^{-1}\left(-\frac{C_{\text {elec }}(t)+p^{t}(t) B_{P}}{\varepsilon}\right)\right) \\
\frac{d p(t)}{d t}=-A^{t} p(t)-\varepsilon C^{t}\left[\gamma_{g}^{\prime}\left(C x(t)-T_{\text {min }}\right)-\gamma_{g}^{\prime}\left(T_{\max }-C x(t)\right)\right]
\end{array}\right.
$$

with the following boundary constraints: $x(0)=x_{0}$ and $p\left(t_{f}\right)=0$.

- Step 4: Decrease $\varepsilon$, initialise $x(t)$ and $p(t)$ with solutions found at Step 3 and restart at Step 2. In this study, the sequence $\left(\varepsilon_{n}\right)$ was chosen such that $\varepsilon_{n}=10^{-\frac{n}{10}}$ with $\mathrm{n}=-90 \ldots+70$.

The presented algorithm was implemented in Matlab R2012b, and run on a Intel Core i7 $(2.8 \mathrm{GHz})$ PC with $16 \mathrm{~GB}$ of RAM, using a single core.

\subsubsection{Sensitivity analysis}

In this study, the goal of the Model Predictive Control (MPC) was the resolution of the constrained optimal control problem that is repeated periodically (controller time step) over a prediction horizon. For MPC applications in buildings, the controller time step may depend on the frequency of new information availability, such as weather forecast, building state estimation, or changes in occupancy. In order to develop an as general as possible MPC, the controller time step was set at 24 hours.

The choice of the prediction horizon of the optimal control problem corresponded to a compromise between precision and calculation time. The sensitivity of the calculated optimal control

$$
{ }^{1} \frac{\partial H_{\varepsilon}}{\partial v}=0 \text { implies } C_{e l e c}(t)+p^{t}(t) B_{P}+\varepsilon \gamma_{u}^{\prime} \circ \phi(v)=0
$$


to the prediction horizon was evaluated. For each prediction horizon tested, the sensitivity analysis consisted in comparing the first 24 hours of the calculated optimal control with a reference. In the following, the reference was the first 24 hours of the calculated optimal control with a prediction horizon of 3 weeks (horizon higher than the largest time constant of the $3^{\text {rd }}$ order model). Two indicators were used in the comparison:

- the mean absolute deviation (MAD) between control (the heating power) calculated by the reference and control calculated with a tested prediction horizon,

- the cost variation.

Prediction horizons comprised between one to five days were tested. Local weather data measured at Chambery (FR) airport, which is $\mathbf{3 0 0}$ metres away from the building, were used. This local weather data corresponded to measurements from January $1^{\text {st }}$ to April $29^{\text {th }}, 2012$. To carry out the sensitivity analysis, three periods were identified in these weather data: a cold and sunny period, a cold and cloudy period, and a transition period. Meteorological characteristics (on the first five days of each period) are listed in Table 3. The input series of outdoor conditions are presented in appendix A.

Table 3: Weather data

\begin{tabular}{|c|c|c|c|}
\hline & $\begin{array}{c}\text { Cold and cloudy } \\
\text { period }\end{array}$ & $\begin{array}{c}\text { Cold and sunny } \\
\text { period }\end{array}$ & Transition period \\
\hline Minimal temperature $\left({ }^{\circ} \mathrm{C}\right)$ & -6.4 & -14.0 & 1.4 \\
\hline Average temperature $\left({ }^{\circ} \mathrm{C}\right)$ & 0.0 & -5.2 & 5.7 \\
\hline Maximal temperature $\left({ }^{\circ} \mathrm{C}\right)$ & 5.2 & 0.9 & 11.3 \\
\hline $\begin{array}{c}\text { Average global horizontal } \\
\text { irradiance }\left(\mathrm{W} \cdot \mathrm{m}^{-2}\right)\end{array}$ & 60 & 63 & 44 \\
\hline $\begin{array}{c}\text { Maximal global horizontal } \\
\text { irradiance }\left(\mathrm{W} \cdot \mathrm{m}^{-2}\right)\end{array}$ & 342 & 456 & 297 \\
\hline
\end{tabular}

The reference and the results of the sensitivity analysis are shown respectively in Table 4 and Table 5. We can observe that a prediction horizon of three days or less was not enough. Indeed, significant differences in the calculated control for each prediction horizon as well as the associated cost were observed. For example, a cold snap appeared during the cold and sunny period and more precisely the successive days were getting colder and colder. In this case, the optimisation algorithm (with a prediction horizon of less than two days) was unable to anticipate the next climatic variations which led to an underestimation of the need for overheating the building explaining the lower cost for the first 24 hours. However, the global cost during the cold snap would be higher due to the lack of anticipation. During the cold and cloudy period and transition period, similar findings can be noted explaining the results. Although the cost was lower for the first 24 hours, the lack of anticipation would lead to a higher global cost for the 3 weeks. Optimisation results with a prediction horizon of four days were close to the reference for each period. Furthermore, adding a day in the prediction horizon led to a marginal improvement (considering the mean absolute deviation). 
Following this sensitivity analysis, a prediction horizon of four days was considered in this study which was a compromise between accuracy and calculation time. However, it is essential to bear in mind that this choice faces practical considerations such as the reliability of weather forecasts.

Table 4: Reference results

\begin{tabular}{|c|c|c|}
\hline & Reference cost $(€)$ & Calculation time (minutes) \\
\hline Cold and cloudy period & 0.37 & 85 \\
\hline Cold and sunny period & 2.64 & 71 \\
\hline Transition period & 0.57 & 75 \\
\hline
\end{tabular}

Table 5: Sensitivity analysis results

\begin{tabular}{|c|c|c|c|c|c|c|c|c|c|}
\hline & \multicolumn{3}{|c|}{ Cold and cloudy period } & \multicolumn{3}{c|}{ Cold and sunny period } & \multicolumn{3}{c|}{ Transition period } \\
\hline $\begin{array}{c}\text { Prediction } \\
\text { horizon }\end{array}$ & $\begin{array}{c}\text { MAD } \\
(\mathrm{W})\end{array}$ & $\begin{array}{c}\text { Cost } \\
\text { variation } \\
(\%)\end{array}$ & $\begin{array}{c}\text { Calculation } \\
\text { time } \\
\text { (minutes) }\end{array}$ & $\begin{array}{c}\text { MAD } \\
(\mathrm{W})\end{array}$ & $\begin{array}{c}\text { Cost } \\
\text { variation } \\
(\%)\end{array}$ & $\begin{array}{c}\text { Calculation } \\
\text { time } \\
\text { (minutes) }\end{array}$ & $\begin{array}{c}\text { MAD } \\
(\text { W) }\end{array}$ & $\begin{array}{c}\text { Cost } \\
\text { variation } \\
(\%)\end{array}$ & $\begin{array}{c}\text { Calculation } \\
\text { time } \\
\text { (minutes) }\end{array}$ \\
\hline 1 day & 98 & -121 & 3 & 824 & -26 & 3 & 151 & -79 & 3 \\
\hline 2 days & 81 & -83 & 5 & 58 & -4 & 5 & 119 & -57 & 5 \\
\hline 3 days & 40 & -29 & 10 & 1.3 & -0.1 & 8 & 73 & -33 & 9 \\
\hline 4 days & 3 & -1.5 & 15 & 0.4 & -0.01 & 10 & 19 & -7 & 12 \\
\hline 5 days & 0.4 & -0.06 & 16 & 0.3 & -0.01 & 13 & 10 & -3 & 14 \\
\hline
\end{tabular}

\section{MPC DESIGN AND IMPLEMENTATION}

MPC design and implementation raises several difficulties as the state estimation of the building model and the design of a low level controller which ensures tracking of setpoints despite disturbances (such as imperfect weather or occupancy forecasts).

\subsection{State estimation}

Knowing the initial state $\left(x(0)=x_{0}\right)$ is necessary to solve the optimal control problem. In our case, the building state could not be determined by direct observation (such as temperature measurements). Therefore a state observer model (Luenberger observer), derived from the system (7), was used to reconstruct the system state [28]. The main objective was to reconstitute an estimate $\hat{x}(t)$ of the state $x(t)$ by only measuring the output $T(t)$ and inputs $P(t)$ and $d(t)$. The error dynamic of such observer is thus:

$$
\frac{d e_{x}(t)}{d t}=(A-L C) e_{x}(t)
$$

where $e_{x}(t)=x(t)-\hat{x}(t)$ and $L$ is the observer gain.

The problem is to ensure asymptotic convergence towards zero of the observer error, which means that the observer gain is chosen such that the eigenvalues of the matrix A - LC are in the left half 
plane. To place the poles and to choose the observer gain, Matlab R2012b was used. A trade-off was necessary between high bandwidth observers (very efficient for estimation but noise sensitive) and low bandwidth ones (slower but less noise sensitive). In this case study, a four days convergence towards zero of the observer error was considered. Consequently, to determine the initial condition of the optimal control problem, it was sufficient to use the driving forces measurements of the previous four days.

\subsection{PI tracking trajectory}

The resolution of the optimal control problem gives the optimal trajectory to follow, noted $\left(T_{r e f}(t), P_{r e f}(t)\right)$. In practice, some differences can be noted between the reference trajectory and the real trajectory. They can be caused by modelling errors or forecast errors (weather, occupancy, etc.). Therefore, a feedback must drive the state to the reference trajectory asymptotically. More precisely, the problem is to calculate the correction $\Delta P$ caused by the error $\Delta T$ in order to follow the reference trajectory. This tracking problem can be solved by using a controller.

The proportional integral (PI) controller was used. The main idea was to add a bias term (corresponding to $P_{r e f}(t)$ ) in the $\mathrm{PI}$ controller. Thus, the final form of the controller algorithm is:

$$
\left\{\begin{array}{c}
\Delta T(t)=T_{\text {ref }}(t)-T_{\text {meas }}(t) \\
P_{\text {con }}(t)=\operatorname{Sat}\left(P_{\text {ref }}(t)+K\left[\Delta T(t)+\frac{1}{T_{i}} \int_{0}^{t} \Delta T(t) d t\right]\right)
\end{array}\right.
$$

where Sat is a saturation function ensuring respect of control constraints, $K$ is the proportional gain and $T_{i}$ is the integral time. The interest of this formulation is twofold. On the one hand, variations in the reference trajectory (transition phase) are better handled with the bias term. On the other hand, the feedback part compensates model or forecast errors.

\subsection{MPC development}

The model predictive controller was implemented and tested in a simulation case study focused on the heating management optimisation. The performance of the proposed energy management approach was simulated using the non-reduced building model (modeled by the COMFIE software) acting as a proxy of the real building, taking into account non-linear phenomena (especially ventilation). The model predictive control process developed in this study corresponded to a four steps process (Figure 7).

The first step is the initialisation where a constant heating setpoint (for example $19^{\circ} \mathrm{C}$ ) is considered. The objective is two-fold. The first goal is to use the COMFIE software to model the building. The balanced truncation method is then used to reduce the reference model. The second objective is to collect data necessary to estimate the initial state of the building (step 2). Because of 
the convergence of the error observer (around 4 days in our case study), it was necessary to have 4 days data of inside temperature, heating power and driving forces (weather data and occupancy). Following the initialisation, the current state of the building is estimated during the second step. Thanks to the data collected at step 1, and the reduced order model of the building, the Luenberger observer, based on the dynamic of the reduced model, is used to estimate the state of the building. This stage is necessary to determine the initial conditions of the optimal control problem (step 3 ). From the state of the building, the optimal control problem can be solved by using the optimisation algorithm presented in $\S 3.2 .2$, and thus an optimal set of heating power over 4 days (prediction horizon) is obtained. During this stage, the reference heating power and the reference trajectory of the inside temperature are calculated. At step 4 , the first 24 hours (control horizon $t_{s}$ ) of the optimal control calculated over 4 days at step 3 is applied to the building. The proportional integral (PI) controller (defined at the $\S 4.2$ ) was used to ensure that the reference trajectory was followed. Indeed, modelling errors or forecast errors may cause some differences between the reference trajectory and the real trajectory. During this stage, the inside temperature and driving forces are measured. Finally, at the end of the 24 hours period, the loop is closed and the current state of the building is estimated thanks to collected measurements: the inside temperature, the heating power calculated by the PI controller, and the driving forces (weather data, occupancy). This estimated state is used to calculate the optimal control for the next day (step 3). 


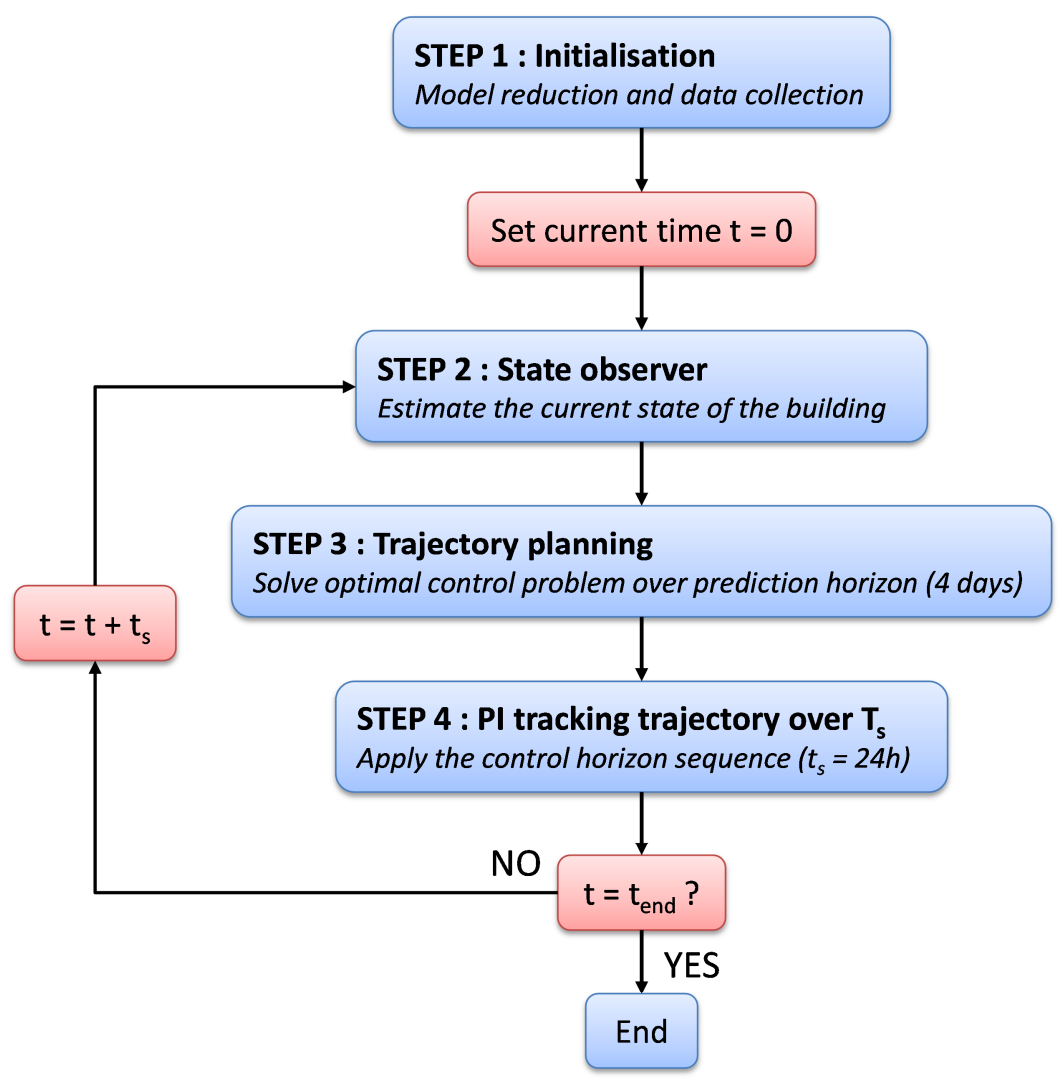

Figure 7 : MPC flowchart

\section{RESULTS}

The objective of the simulation case study was to shift the heating load in the building. The model predictive controller was tested to control the heating system during a cold week corresponding to measurements from February $2^{\text {nd }}$ to February $8^{\text {th }} 2012$ (Figure 8) when the electricity demand was at its highest.

The reliability of the MPC was assessed by performing a robustness analysis. The goal was to evaluate the impact of forecasting errors (weather and occupancy) on the heating control strategy calculated by the MPC, and to assess the MPC's behaviour in more realistic conditions. In this case study, no measurement errors were taken into account. This is a limitation which could be investigated in a future study. To compute the MPC, a prediction horizon of four days and a control horizon of one day were used.

Two simulation cases studies were considered which differed in the occupancy scenario used during the simulation. The two occupancy scenarios were extracted from the average statistical scenario generated using the stochastic occupancy model (§ 2.1). They modelled two families (as a reminder, a three people household with high performances appliances and lighting) with a low (respectively high) electricity consumption due to appliances and lighting (identified by Family 1 and 
Family 2 respectively). The Family 1 (respectively Family 2 ) consumed $17 \%$ less (respectively $16 \%$ more) electricity than the average statistical scenario. Figure 9 presents the internal gains for each occupancy scenario.

The following indicators were used to evaluate the MPC's performances:

- the cumulative cost due to heating consumption and electricity appliances,

- the percentage of heating energy consumption which is load shifted during high peak hours, compared to a $19^{\circ} \mathrm{C}$ constant temperature setpoint strategy,

- the percentage of heating energy consumption which is load shifted during peak hours, compared to a $19^{\circ} \mathrm{C}$ constant temperature setpoint strategy.

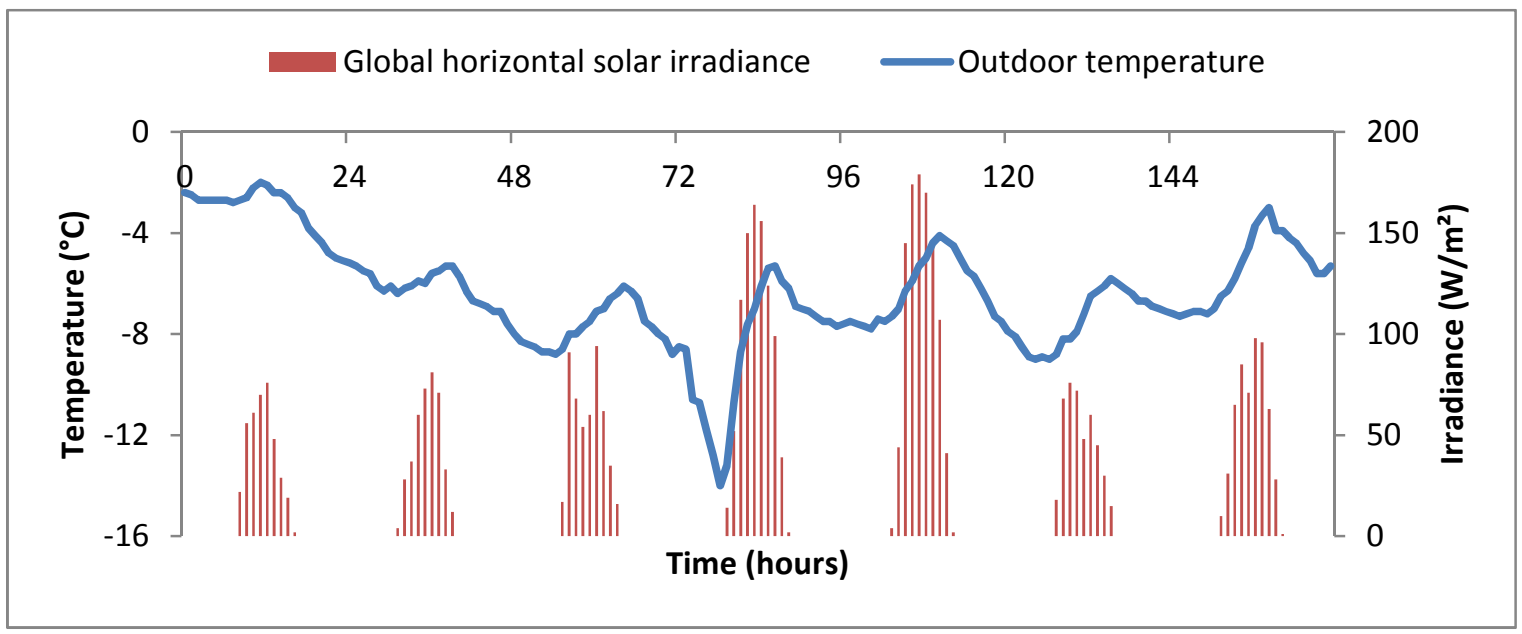

Figure 8: Climatic conditions for the studied period

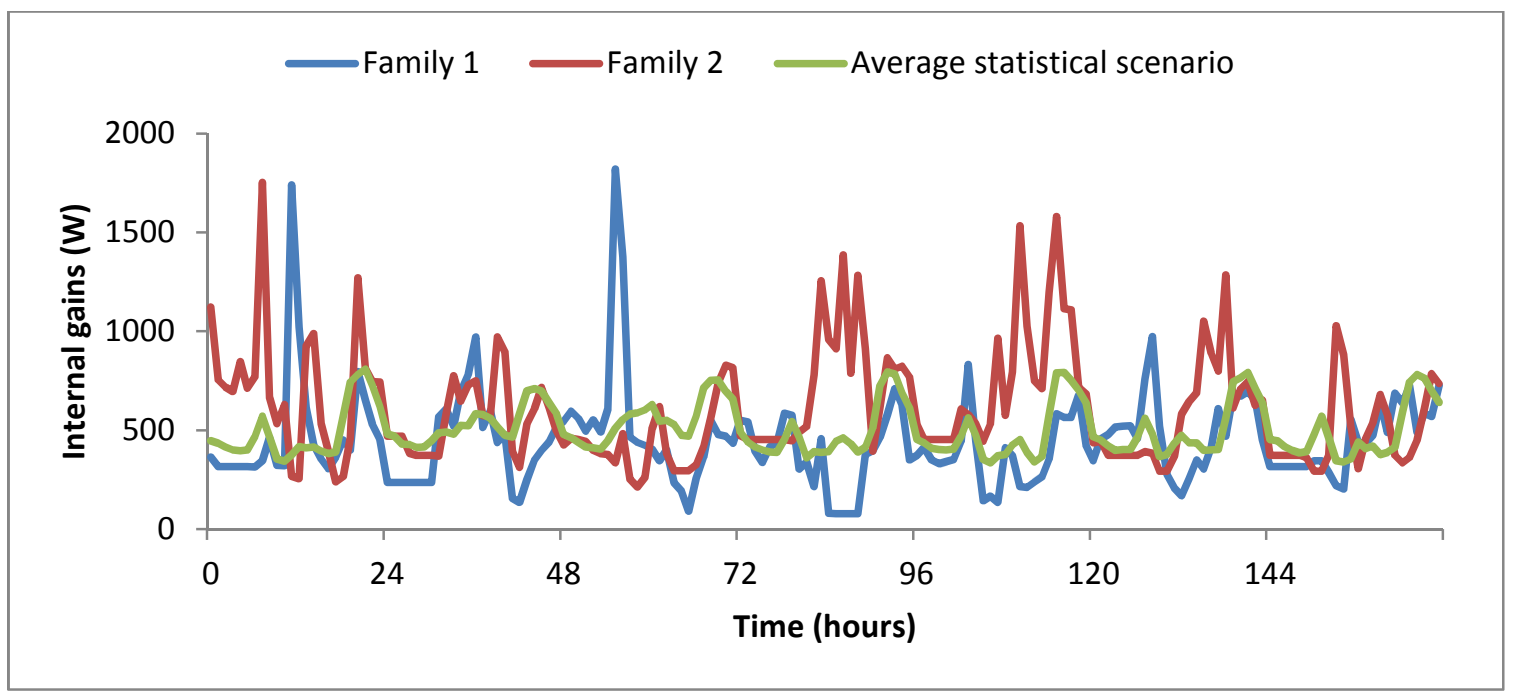

Figure 9: Internal gains for each occupancy scenario

For each case study, four control strategies were tested. Firstly, a reference scenario with a $19^{\circ} \mathrm{C}$ constant temperature setpoint strategy was considered with the actual weather and occupancy scenarios. This strategy enabled us to evaluate the electricity demand during a cold week. Secondly, the theoretical MPC was tested, which was defined as optimal control with perfect knowledge of all 
disturbances acting upon the building. This control strategy was used to determine the performance limit of MPC, in the ideal case of perfect weather prediction and perfect occupancy prediction (Family 1 or Family 2 according to the case study). Thirdly, the MPC with an underestimation of temperature and solar radiation forecasts (weather forecasts) and using the average statistical scenario for occupancy forecasts was examined. Fourthly, the MPC with an overestimation of weather forecasts and using the average statistical scenario for occupancy forecasts was tested. The last two MPC simulations enabled us to evaluate the impact of occupancy and weather forecasts errors on the MPC's performance. The occupancy and weather forecasts considered for each case study are listed in Table 6.

Table 6: Occupancy and weather forecasts for each control strategy

\begin{tabular}{|c|c|c|c|}
\hline \multicolumn{4}{|c|}{ Case study 1: Family 1 occupancy } \\
\hline & MPC (theoretical) & MPC (underestimation) & MPC (overestimation) \\
\hline $\begin{array}{l}\text { Outdoor temperature } \\
\text { forecasts }\end{array}$ & True value & True value $-1^{\circ} \mathrm{C}$ & True value $+1^{\circ} \mathrm{C}$ \\
\hline $\begin{array}{l}\text { Global horizontal } \\
\text { radiation forecasts }\end{array}$ & True value & True value - $20 \%$ & True value $+20 \%$ \\
\hline Occupancy forecasts & $\begin{array}{c}\text { Family } 1 \\
\text { (low electricity } \\
\text { consumption) }\end{array}$ & $\begin{array}{c}\text { Average statistical } \\
\text { scenario }\end{array}$ & $\begin{array}{l}\text { Average statistical } \\
\text { scenario }\end{array}$ \\
\hline \multicolumn{4}{|c|}{ Case study 2: Family 2 occupancy } \\
\hline & MPC (theoretical) & MPC (underestimation) & MPC (overestimation) \\
\hline $\begin{array}{c}\text { Outdoor temperature } \\
\text { forecasts }\end{array}$ & True value & True value $-1^{\circ} \mathrm{C}$ & True value $+1^{\circ} \mathrm{C}$ \\
\hline $\begin{array}{c}\text { Global horizontal } \\
\text { radiation forecasts }\end{array}$ & True value & True value - $20 \%$ & True value $+20 \%$ \\
\hline Occupancy forecasts & $\begin{array}{c}\text { Family } 2 \\
\text { (high electricity } \\
\text { consumption) }\end{array}$ & $\begin{array}{c}\text { Average statistical } \\
\text { scenario }\end{array}$ & $\begin{array}{l}\text { Average statistical } \\
\text { scenario }\end{array}$ \\
\hline
\end{tabular}

As an example, indoor temperature variations for case study 2 and the heating power calculated by the different MPC are presented respectively in Figure 10 and Figure 11. The indoor temperature was always within the range of temperature constraints $\left[19^{\circ} \mathrm{C}, 24^{\circ} \mathrm{C}\right]$. As expected, when the weather forecasts data were overestimated, temperatures were slightly lower. The reverse was observed when the weather forecasts data were underestimated. 


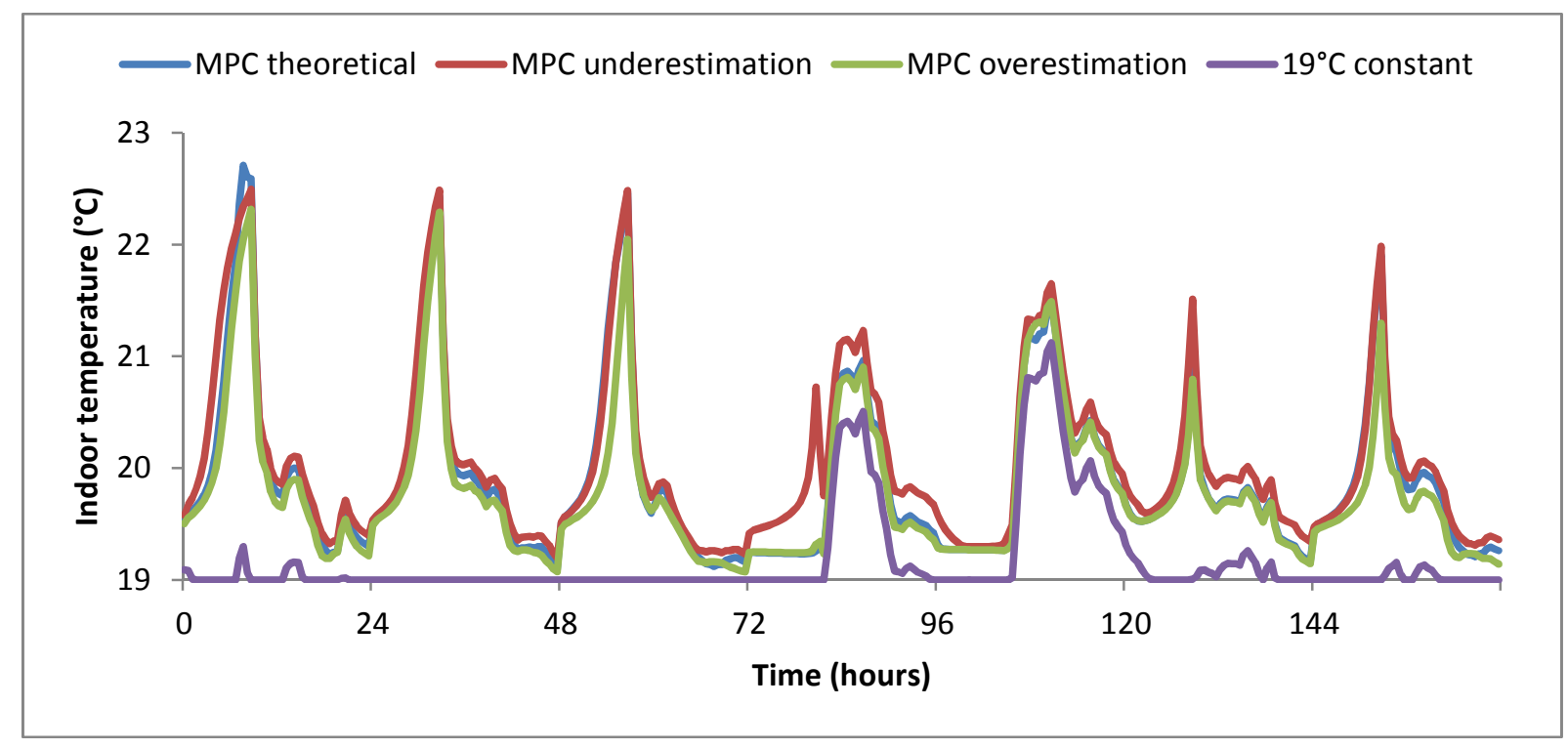

Figure 10: Evolution of indoor temperature for case study 2

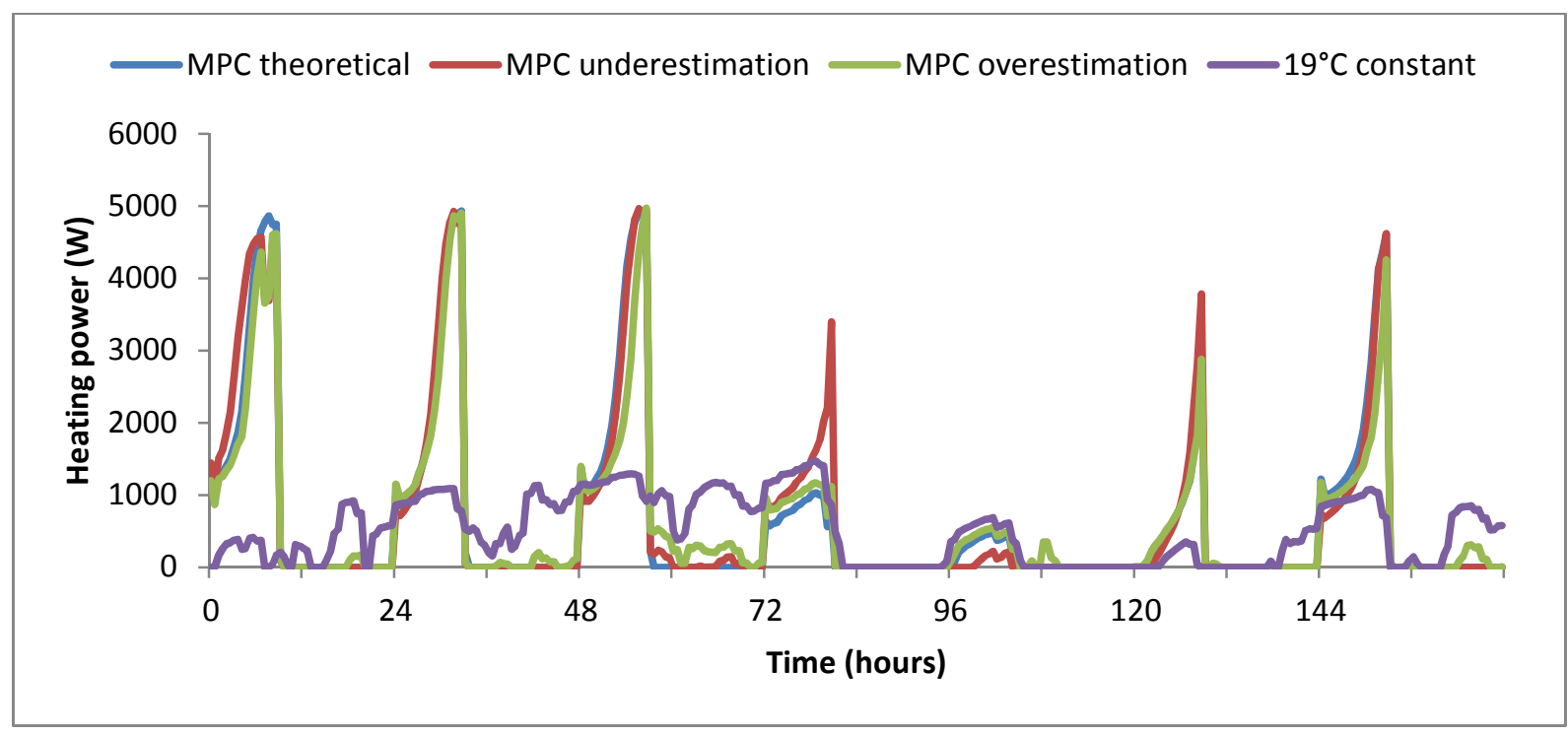

Figure 11: Heating power calculated for case study 2

Quantitative results are presented in Tables 7-8. For each case study, the theoretical MPC had a lowest cumulative cost than the reference scenario $(13 \%$ or $7 \%$ less according to the case study). Furthermore, the heating power was mainly used during the off-peak periods. For instance, $100 \%$ of the electricity consumed during high peak hours for heating was load shifted with the theoretical MPC. This was also true during peak hours, where almost $100 \%$ of the electricity consumption was load shifted for each case study. With a $19^{\circ} \mathrm{C}$ constant temperature setpoint strategy (reference scenario), the electricity consumed during peak hours for heating represented $55 \%$ of the total energy consumed for case study 1 (respectively $33 \%$ for case study 2 ). Similarly, the electricity consumed during high peak hours represented $67 \%$ of the total energy consumed for case study 1 (respectively $52 \%$ for case study 2). Consequently, due to the thermal mass of the building, 
energy was stored in the building, and allowed to switch off the heating system during peak and high peak hours. This energy storage was accompanied by an increase in the energy consumption by $24 \%$ for case study 1 (respectively $29 \%$ for case study 2). But the cost was lower due to the considered tariff.

When forecast errors were taken into account, we can observe an increase in the cumulative cost compared to the theoretical MPC. For case study 1 , the cumulative cost increased by $2 \%$ with an underestimation of weather forecasts data and by $5 \%$ with an overestimation of weather forecasts data. However, these costs were reduced compared to the reference scenario (reduction of 11 and $8 \%$ respectively). We can also observe a slightly decrease in electricity consumption load shifted (during peak and high peak periods) with an underestimation of weather forecasts data for both cases studies. This decrease is explained by the internal gains due to the Family 1 which were sometimes higher than the average statistical scenario (Figure 9).

The observation is different when the weather forecasts data were overestimated. For instance for case study 2 , the electricity consumption load shifted was decreased by around $15 \%$ for peak or high peak periods compared to the theoretical MPC. Due to the overestimation of weather forecasts data, the MPC tended to underestimate the heating load. Consequently, when the control was applied in real conditions, it was necessary to heat during peak and high peak periods to follow the reference trajectory (due to internal gains prediction errors), causing an increase in the cumulative cost. For case study 1 , the same problem is reinforced due to the occupancy scenario (Family 1) which had less internal gains. We can thus observe the interactions between the occupancy scenarios and the weather forecasts.

Table 7: Results case study 1 (Family 1 occupancy)

\begin{tabular}{|l|c|c|c|c|}
\hline & $19^{\circ} \mathrm{C}$ constant & MPC (theoretical) & $\begin{array}{c}\text { MPC } \\
\text { (underestimation) }\end{array}$ & $\begin{array}{c}\text { MPC } \\
\text { (overestimation) }\end{array}$ \\
\hline Cumulative cost $(€)$ & 21.9 & 19 & 19.5 & 10.2 \\
\hline $\begin{array}{l}\text { Electricity consumed } \\
\text { during off-peak hours } \\
\text { for heating (kWh) }\end{array}$ & 56.2 & 135.3 & 136.2 & 13.1 \\
\hline $\begin{array}{l}\text { Electricity consumed } \\
\text { during peak hours for } \\
\text { heating (kWh) }\end{array}$ & 29.3 & 0.4 & 0.8 & 6.8 \\
\hline $\begin{array}{l}\text { Electricity consumed } \\
\text { during high peak } \\
\text { hours for heating } \\
\text { (kWh) }\end{array}$ & 23.6 & 0 & 1.4 & 55 \\
\hline $\begin{array}{l}\text { High peak hours load } \\
\text { shifted for heating (\%) }\end{array}$ & - & 99 & 97 & 71 \\
\hline $\begin{array}{l}\text { Peak hours load } \\
\text { shifted for heating (\%) }\end{array}$ & - & 100 & 94 & $19 / 22.4$ \\
\hline$T_{\min } / T_{\max }\left({ }^{\circ} \mathrm{C}\right)$ & $19 / 20.5$ & $19.1 / 23.3$ & $19 / 22.6$ & \\
\hline
\end{tabular}


Table 8: Results case study 2 (Family 2 occupancy)

\begin{tabular}{|l|c|c|c|c|}
\hline & $19^{\circ} \mathrm{C}$ constant & MPC (theoretical) & $\begin{array}{c}\text { MPC } \\
\text { (underestimation) }\end{array}$ & $\begin{array}{c}\text { MPC } \\
\text { (overestimation) }\end{array}$ \\
\hline Cumulative cost (€) & 22.8 & 21.1 & 21.5 & 21.2 \\
\hline $\begin{array}{l}\text { Electricity consumed } \\
\text { during off-peak hours } \\
\text { for heating (kWh) }\end{array}$ & 47.3 & 108.4 & 112.2 & 98.2 \\
\hline $\begin{array}{l}\text { Electricity consumed } \\
\text { during peak hours for } \\
\text { heating (kWh) }\end{array}$ & 19 & 0.3 & 0.7 & 3.5 \\
\hline $\begin{array}{l}\text { Electricity consumed } \\
\text { during high peak } \\
\text { hours for heating } \\
\text { (kWh) }\end{array}$ & 18 & 0 & 0.3 & 2.6 \\
\hline $\begin{array}{l}\text { High peak hours load } \\
\text { shifted for heating (\%) }\end{array}$ & - & 98 & 96 & 82 \\
\hline $\begin{array}{l}\text { Peak hours load } \\
\text { shifted for heating }(\%)\end{array}$ & - & 100 & 98 & 86 \\
\hline$T_{\left.\text {min } / T_{\text {max }}{ }^{\circ} \mathrm{C}\right)}$ & $19 / 21.1$ & $19.1 / 22.8$ & $19.1 / 22.6$ & $19.1 / 22.4$ \\
\hline
\end{tabular}

\section{CONCLUSION}

MPC framework and an interior penalty algorithm were used to study load shifting of heating systems in an energy efficient building. A reduced model derived from advanced building simulation software and a time-continuous algorithm were used to control the heating power in real time. First of all, the results showed that the balanced truncation method and the interior penalty algorithm were well suited for real time control problems and yielded precise results. Considering an experimental passive house (a well insulated building with a high thermal mass), it was possible to shift the heating load to off-peak periods thanks to the high thermal mass of the building. The load shifting enabled to decrease the heating cost by as much as 6 to $13 \%$ compared to a $19^{\circ} \mathrm{C}$ constant temperature setpoint control strategy according to the assumed electricity prices schedule. Finally, a sensitivity assessment showed the MPC's robustness to occupancy and weather forecasting errors.

Despite the good results shown in the simulation cases studies, the effectiveness of the proposed MPC framework remains to be shown in real conditions. In particular, the MPC's robustness to measurement uncertainty should be studied. Finally, the method could be extended for multi-zone buildings but this would require to adapt the optimisation algorithm to take into account the interaction between several zones of the buildings. 


\section{ACKNOWLEDGMENT}

This work was supported by the French Research National Agency (ANR) through the PRECCISION project (ANR-12-VDBU-0006), part of "Villes et Bâtiments Durables (VBD) 2012" program.

\section{NOMENCLATURE}

\subsection{Latin}

$A$

state matrix

$B \quad$ input matrix

$B_{d} \quad$ input matrix related to external factors

$B_{P} \quad$ input matrix related to heating power

C output matrix

C bounded closed convex set

$C_{\text {elec }} \quad$ electricity price $[€]$

$C_{m} \quad$ thermal capacity of the mesh $[\mathrm{J} / \mathrm{K}]$

D feedforward matrix

$d \quad$ influence of the outside temperature, solar fluxes, occupancy and other appliances $[\mathrm{W}]$

$e_{x} \quad$ observer error

$f \quad$ dynamical system

$H_{\varepsilon} \quad$ Hamiltonian of the penalised problem

J cost function

$K \quad$ proportional gain $\left[\mathrm{W} /{ }^{\circ} \mathrm{C}\right]$

$k \quad$ positive parameter

$\mathcal{L} \quad$ smooth real-valued function

$L \quad$ observer gain

$m \quad$ control dimension

$n \quad$ state dimension (reduced model) 


\begin{tabular}{|c|c|}
\hline$P$ & heating power [W] \\
\hline$p$ & adjoint state \\
\hline$P_{\text {con }}$ & controller heating power $[\mathrm{W}]$ \\
\hline$P_{\max }$ & maximal heating power $[\mathrm{W}]$ \\
\hline$P_{\text {min }}$ & minimal heating power $[\mathrm{W}]$ \\
\hline$P_{\text {ref }}$ & optimal control [W] \\
\hline$P_{\varepsilon}^{*}$ & optimal control of the penalised problem [W] \\
\hline$q$ & state dimension (reference model) \\
\hline$\dot{Q}_{G}$ & solar and internal gains [W] \\
\hline$\dot{Q}_{L}$ & linearised heat losses [W] \\
\hline Sat & saturation function \\
\hline$T$ & indoor temperature $\left[{ }^{\circ} \mathrm{C}\right]$ \\
\hline$T_{i}$ & integral time $[\mathrm{s}]$ \\
\hline$T_{m}$ & temperature of the mesh $\left[{ }^{\circ} \mathrm{C}\right]$ \\
\hline$T_{\max }$ & maximal acceptable temperature in heating zone $\left[{ }^{\circ} \mathrm{C}\right]$ \\
\hline$T_{\min }$ & minimal acceptable temperature in heating zone $\left[{ }^{\circ} \mathrm{C}\right]$ \\
\hline$T_{\text {ref }}$ & optimal trajectory $\left[{ }^{\circ} \mathrm{C}\right]$ \\
\hline$t$ & time $[s]$ \\
\hline$t_{f}$ & final time of the optimisation period $[\mathrm{s}]$ \\
\hline$t_{s}$ & control horizon $[\mathrm{s}]$ \\
\hline$u$ & driving forces [W] \\
\hline$U \cap X$ & control and state constraints \\
\hline$x$ & state of the building \\
\hline$\hat{x}$ & estimated state of the building \\
\hline$y$ & zone temperature $\left[{ }^{\circ} \mathrm{C}\right]$ \\
\hline
\end{tabular}

\subsection{Greek}

$\gamma_{g}($.$) \quad state penalty function$

$\gamma_{u}($.$) \quad control penalty function$ 


$\begin{array}{ll}\Delta T & \text { difference between the reference trajectory and the real trajectory }\left[{ }^{\circ} \mathrm{C}\right] \\ \varepsilon & \text { positive parameter } \\ \varepsilon_{0} & \text { positive parameter } \\ \varepsilon_{n} & \text { sequence of positive parameter decreasing to zero } \\ v & \text { variable change of the heating power } \\ v_{\varepsilon}^{*} & \text { variable change of the heating power } \\ \phi & \text { generalised saturation function }\end{array}$

\section{REFERENCES}

[1] ADEME, Les Chiffres clé du bâtiment - Énergie Environnement, Agence de l'Environnement et de la Maîtrise de I'Énergie. http://multimedia.ademe.fr/catalogues/chiffres-cles-batiment2012/, 2012 (accessed July 31, 2013).

[2] C.R. Touretzky, M. Baldea, Integrating scheduling and control for economic MPC of buildings with energy storage, Journal of Process Control. 24 (2014) 1292-1300. doi:10.1016/j.jprocont.2014.04.015.

[3] N. Beeker, P. Malisani, N. Petit, An optimization algorithm for load-shifting of large sets of electric hot water tanks, in: Proceedings of the 29th international conference on Efficiency, Cost, Optimization, Simulation and environmental impact of energy systems, Portorož, Slovenia, June 19-23, 2016.

[4] N. Kelly, J. Hong, I. Richardson, M. Thomson, The influence of thermal storage on microgeneration flexibility, in: Proceedings of the 2nd International Conference in Microgeneration Technologies, Glasgow, Scotland, April 04-06, 2011.

[5] B. Favre, B. Peuportier, Application of dynamic programming to study load shifting in buildings, Energy and Buildings 82 (2014) 57-64. doi:10.1016/j.enbuild.2014.07.018.

[6] G.P. Henze, D.E. Kalz, S. Liu, C. Felsmann, Experimental Analysis of Model-Based Predictive Optimal Control for Active and Passive Building Thermal Storage Inventory, HVAC\&R Research 11 (2005) 189-213. doi:10.1080/10789669.2005.10391134.

[7] C.R. Touretzky, M. Baldea, A hierarchical scheduling and control strategy for thermal energy storage systems, Energy and Buildings 110 (2016) 94-107. doi:10.1016/j.enbuild.2015.09.049.

[8] G. Fraisse, C. Viardot, O. Lafabrie, G. Achard, Development of a simplified and accurate building model based on electrical analogy, Energy and Buildings 34 (2002) 1017-1031. doi:10.1016/S0378-7788(02)00019-1.

[9] A. Mechaqrane, M. Zouak, A comparison of linear and neural network ARX models applied to a prediction of the indoor temperature of a building, Neural Comput. Appl. 13 (2004) 32-37. doi:10.1007/s00521-004-0401-8.

[10] J. Ma, S.J. Qin, T. Salsbury, Model predictive control of building energy systems with balanced model reduction, in: 2012 Am. Control Conf. ACC, 2012: pp. 3681-3686. doi:10.1109/ACC.2012.6315516. 
[11] E. Vorger, P. Schalbart, B. Peuportier, Integration of a comprehensive stochastic model of occupancy in building simulation to study how inhabitants influence energy performance, in: Proceedings PLEA 2014, Ahmedabad, India, December 16-18, 2014.

[12] B. Peuportier, I. Blanc-Sommereux, Simulation tool with its expert interface for the thermal design of multizone buildings, Int. J. Sol. Energy. 8 (1990) 109-120. doi:10.1080/01425919008909714.

[13] A. Neveu, Étude d'un code de calcul d'évolution thermique d'une enveloppe de bâtiment, PhD diss., Université Pierre et Marie Curie, Paris VI, 1984.

[14] P. Bacot, Analyse modale des systèmes thermiques, PhD diss., École Nationale Supérieure des Mines de Paris, 1984.

[15] G. Lefebvre, Analyse et réduction modales d'un modèle de comportement thermique du bâtiment, PhD diss., Université Pierre et Marie Curie, 1987.

[16] B. Peuportier, Bancs d'essais de logiciels de simulation thermique, in: Proceedings of Journée SFT-IBPSA "Outils de simulation thermoaéraulique du bâtiment", La Rochelle, France, march 31, 2005.

[17] A. Brun, C. Spitz, E. Wurtz, L. Mora, Behavioural comparison of some predictive tools used in a low-energy building, in: Proceedings of Elev. Int. IBPSA Conf., Glasgow, Scotland, July 27-30, 2009.

[18] F. Munaretto, T. Recht, P. Schalbart, B. Peuportier, Empirical validation of different internal superficial heat transfer models on a full-scall passive house, Journal of Building Performance Simulation 0 (0):1-22. https://doi.org/10.1080/19401493.2017.1331376.

[19] T. Recht, F. Munaretto, P. Schalbart, B. Peuportier, Analyse de la fiabilité de COMFIE par comparaison à des mesures. Application à un bâtiment passif., in: Proc. IBPSA Fr., Arras, 2014: p. 8.

[20] G. Lefebvre, La méthode modale en thermique: Modélisation, simulation, mise en oeuvre, applications, Ellipses, 2007.

[21] A. Sempey, C. Inard, C. Ghiaus, C. Allery, Fast simulation of temperature distribution in air conditioned rooms by using proper orthogonal decomposition, Build. Environ. 44 (2009) 280289. doi:10.1016/j.buildenv.2008.03.004.

[22] A.A. Yahia, E.P.D. Barrio, Thermal systems modelling via singular value decomposition: direct and modular approach, Appl. Math. Model. 23 (1999) 447-468. doi:10.1016/S0307904X(98)10091-4.

[23] B. Moore, Principal component analysis in linear systems: Controllability, observability, and model reduction, IEEE Trans. Autom. Control. 26 (1981) 17-32. doi:10.1109/TAC.1981.1102568.

[24] E. Palomo Del Barrio, G. Lefebvre, P. Behar, N. Bailly, Using model size reduction techniques for thermal control applications in buildings, Energy and Buildings. 33 (2000) 1-14. doi:10.1016/S0378-7788(00)00060-8.

[25] P. Malisani, F. Chaplais, N. Petit, An interior penalty method for optimal control problems with state and input constraints of nonlinear systems, Optim. Control Appl. Methods. (2014) n/an/a. doi:10.1002/oca.2134.

[26] L.S. Pontryagin, V.G. Boltyanski, R.V. Gamkrelidze, E.F. Mishchenko, The Mathematical Theory of Optimal Processes, Interscience Publishers John Wiley \& Sons, Inc.: New York, London, 1962.

[27] P. Malisani, Dynamic control of energy in buildings using constrained optimal control by interior penalty, PhD diss., École Nationale Supérieure des Mines de Paris, 2012. 
[28] D.G. Luenberger, Introduction to dynamic systems; theory, models, and applications, John Wiley \& Sons, New York, 1979.

\section{APPENDIX A}

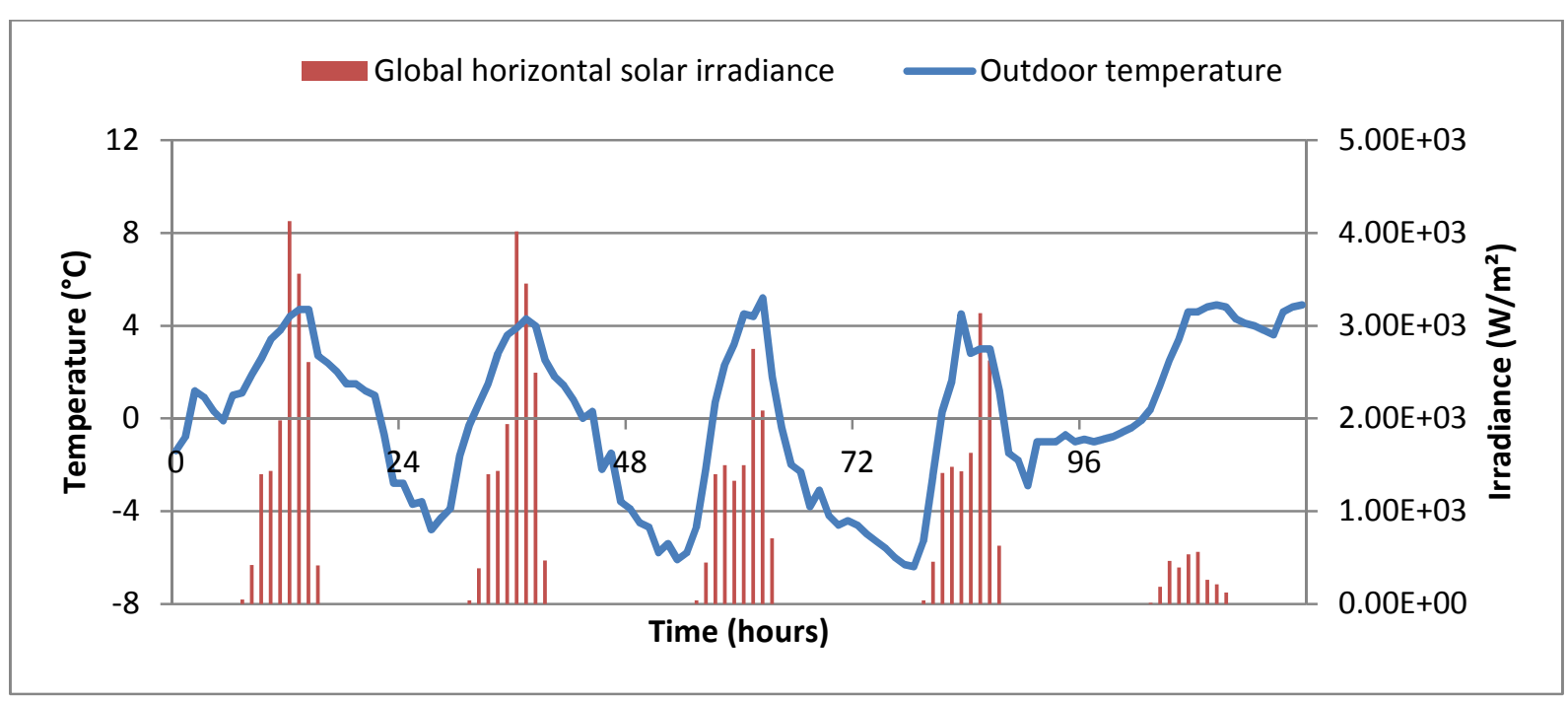

Figure 12: Climatic conditions (cold and cloudy period)

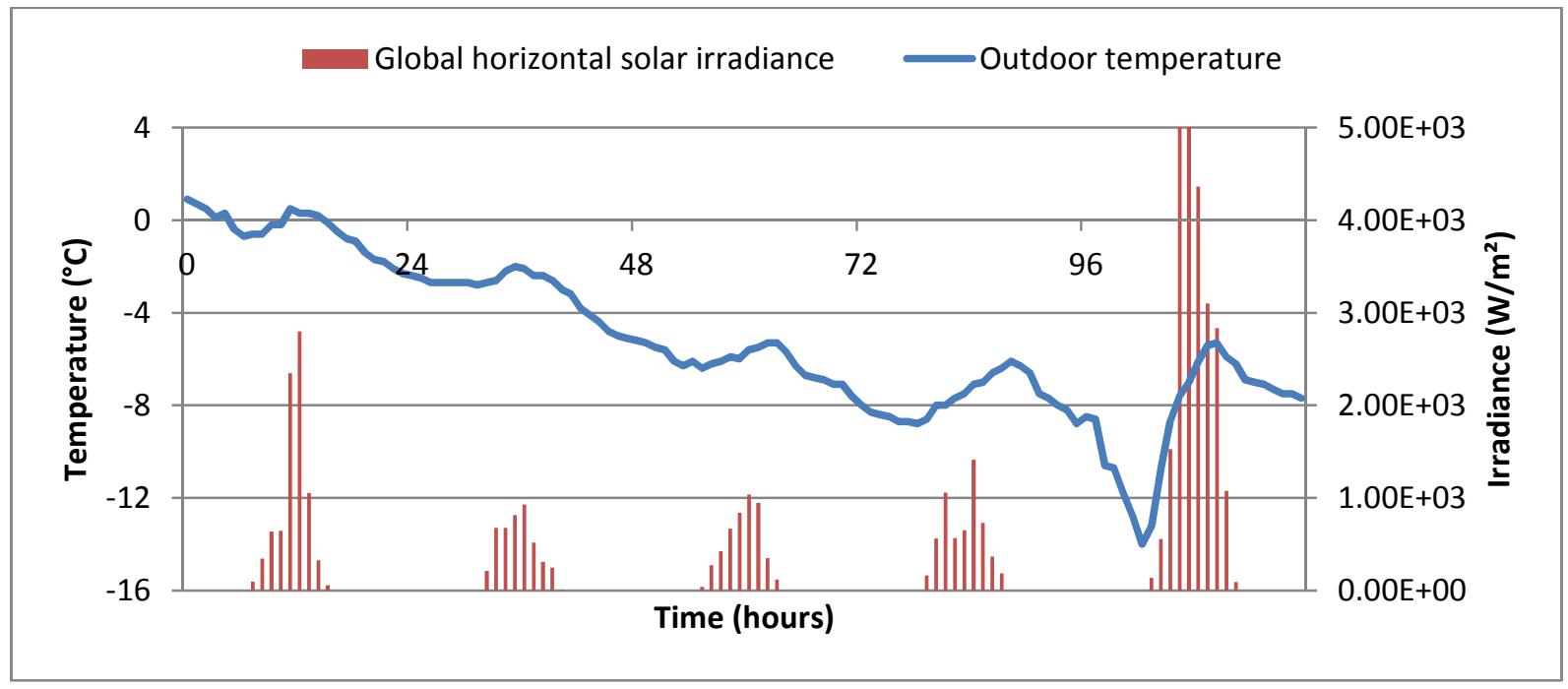

Figure 13: Climatic conditions (cold and sunny period) 


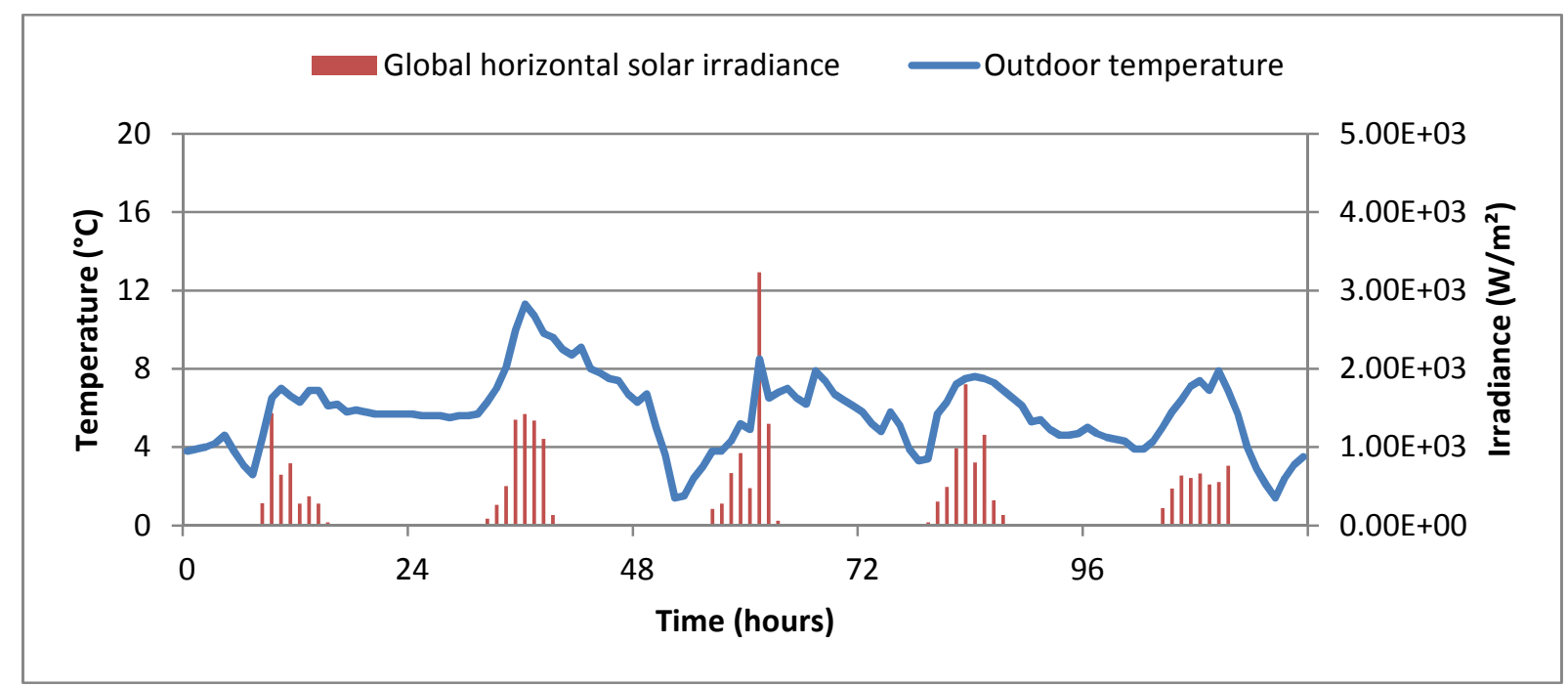

Figure 14: Climatic conditions (transition period) 